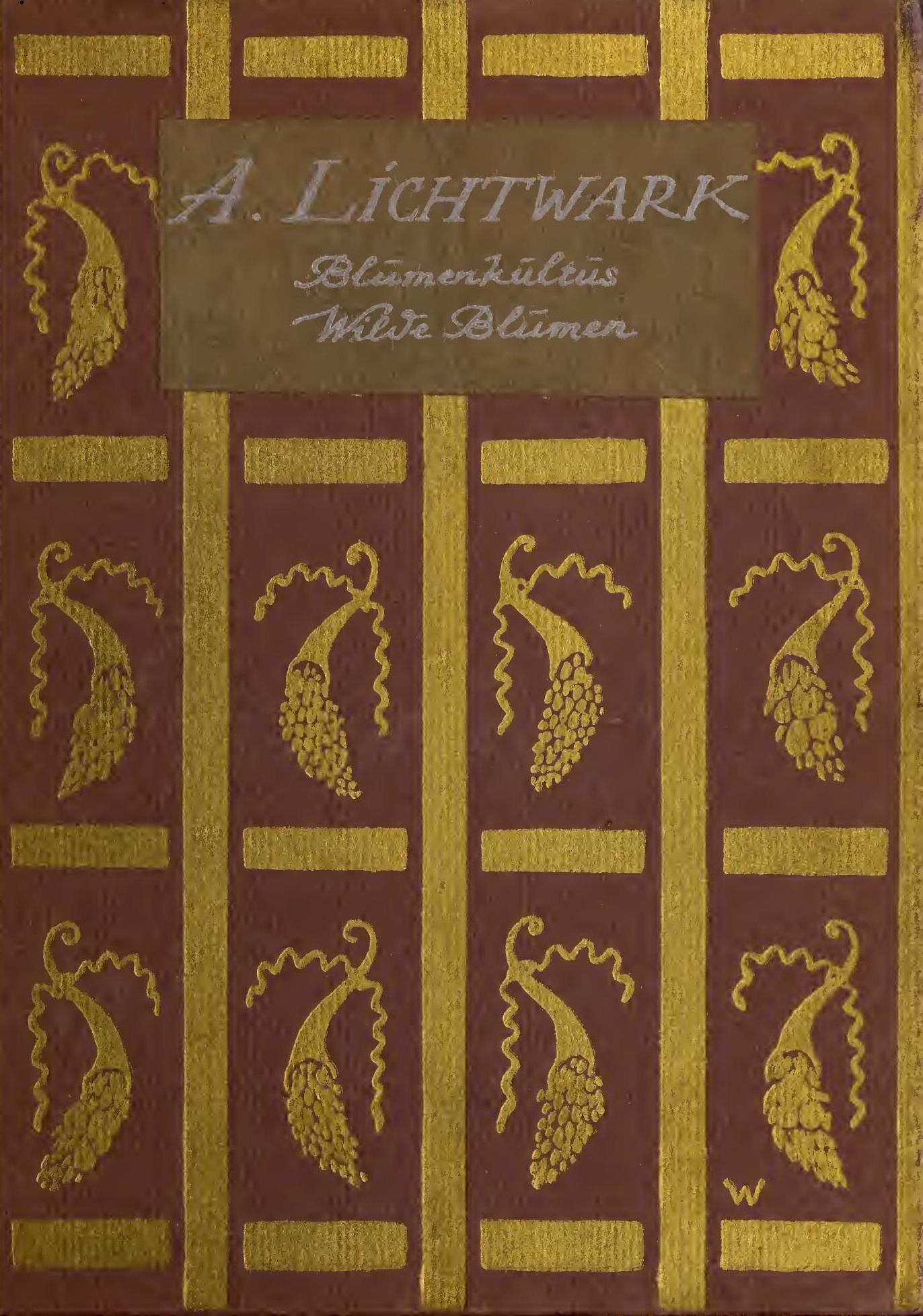



Digitized by the Internet Archive in 2014 


\section{BLUMENKULTUS - WILDE BLUMEN}

$$
\text { V O L K S A U S G A B E }
$$




\section{DIE GRUNDLAGEN}

DER

\section{KÜNSTLERISCHEN BILDUNG}

STUDIEN

VON

ALFRED LICHTWARK

BRUNO CASSIRER • BERLIN 1907 


\section{ALFRED LICHTWARK}

\section{B L U M E K UL T US}

WILDE BLUMEN

ZWEITE, ERWEITERTE AUFLAGE

$$
\text { V OLKS A US G A B E }
$$

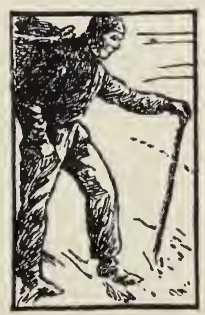

BRUNO CASSIRER · BERLIN 1907 



\section{DER PRASLDENTIN}

DER

GESELLSCHAFT HAMBURGER KUNSTFREUNDE

FRAU MARIA ZACHARIAS

GEWIDMET 



\section{INHALT}

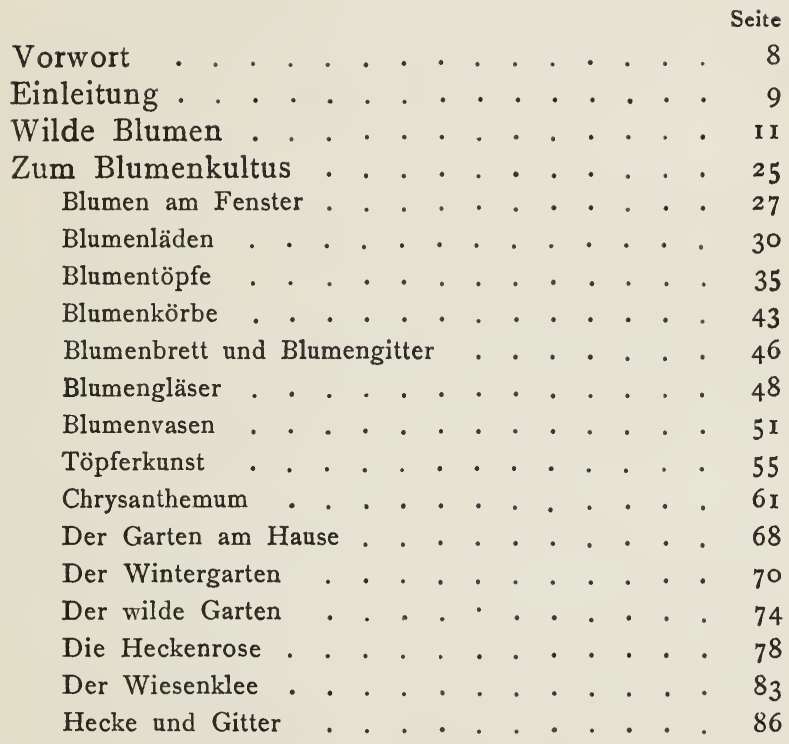




\title{
VORWORT
}

\section{ZUR \\ ZWEITEN AUFLAGE}

\begin{abstract}
Der zweiten, stellenweise überarbeiteten und erweiterten Auflage habe ich die Kapitel von Seite 74 bis Seite 90 hinzugefügt.
\end{abstract}

L. 


\section{EINLEITUNG}

Eine neue Leidenschaft für die Blume ist im Erwachen.

Man hat zwar in der vergangenen Generation Blumen gepflegt und Blumenschmuck verwendet, aber nicht entfernt mit dem tiefen künstlerischen Interesse wie in der Kultur des siebzehnten und achtzehnten Jahrhunderts. Wo sind in der bildenden Kunst der Mitte unseres Jahrhunderts die Blumenstücke, die sich denen der Holländer, Franzosen, und unseres Hamburgischen Blumenmalers Tamm an Kenntnis und Gefühl vergleichen liessen? Wo war im kleinen Stadtgarten mit seinen Rasen und Büschen die Blume geblieben? Und wie durchaus unkünstlerisch war der Blumenschmuck im Zimmer und die Leistung der Straussbinderei.

Der Umschwung hat sich sehr schnell vollzogen, aber noch ist viel zu thun, um das neuerwachte künstlerische Interesse für die Blume in den Dienst der ästhetischen Bildung zu stellen.

In den Vorlesungen an der Kunsthalle und 
in den Versammlungen der Gesellschaft Hamburgischer Kunstfreunde habe ich die einschlagenden Fragen wiederholt $\mathrm{zu}$ behandeln versucht. Die vorliegende Studie enthält, wie die früher erschienene "Makartbouquet und Blumenstrauss" einige Ergebnisse dieser Besprechungen. "Makartbouquet und Blumenstrauss" sollte ein Bild der Situation entwerfen; die Studie "Wilde Blumen" den Hintergrund vertiefen, die kurzen Aufsätze zum Blumenkultus allerlei Wünsche darlegen und in grossen Zügen den äusseren Apparat überblicken, dessen es für die Behandlung des Blumenschmuckes auf dem Tisch und am Fenster bedarf. Beide Aufsätze sind im Jahrbuch der Gesellschaft Hamburgischer Kunstfreunde (als Manuskript gedruckt) zuerst erschienen.

Die bewusste Freude an der ästhetischen Schönheit der Blume bildet einen der wichtigsten Ausgangspunkte der künstlerischen Erziehung des Individuums.

Wer sich gewöhnt hat, nicht nur mit dem überkommenen mehr sentimentalen Interesse $\mathrm{zu}$ sehen, sondern die Erscheinung der Blume jedesmal mit den frischen Augen des Entdeckers in sich aufzunehmen, der wird empfinden, wie die Kraft des Urteils über alles, was in Kunst und Kunstgewerbe Farbe heisst, in ihm erstarkt. 


\section{WILDE BLUMEN}

$\mathrm{B}$ is auf den heutigen Tag bin ich mir nicht klar darüber, ob die ästhetische Befähigung des menschlichen Auges mehr den Insekten zu danken ist oder mehr den Vögeln. Es kommt auf die Stimmung an, wohin ich mich neige.

Dem Menschen selber traue ich nicht viel urangeborene Begabung zu: er hat eine gar zu talentlose Verwandtschaft.

Denn die Wesen, die ihm nach ihrem Körperbau am nächsten stehen, sind ästhetisch sehr schwach begabt. Kein Säugetier ist nennenswert musikalisch. Ihre Stimmen sind entsetzlich roh und unkultiviert. Ross und Kamel werden von unsern Schlacht- und Marschweisen aufgestachelt, aber wir haben von ihnen noch kein Urteil gehört, ob sie wirklich von der Musik gepackt werden, oder ob ihnen nicht blos der Rhythmus durch die Glieder fährt, deren Bewegung das natürliche Gefühl dafür in ihrer Seele erzeugt hat. Das Auge der Säugetiere ist vielleicht noch schwächer veranlagt als ihr Ohr. In ihrer Klei- 
dung herrscht eine erschreckende Monotonie: Weiss und Schwarz bilden die Pole, deren Verbindungen direkt über das Grau oder in etwas weiterem Bogen über das Braun führen. Kein Blau, kein Grün, kein eigentliches Rot oder Gelb und keine Spur von dem metallischen Hauch, der die Farben auf dem Gefieder der Vögel, dem Panzer der Insekten, den Flügeln der Schmetterlinge $\mathrm{zu}$ satter Glut steigert. Der Mandrill mit seinen scheusslichen blauen Flecken, die aber Haut, nicht Haar sind, und der Maulwurf vom Kap mit metallischem Lüster im Haarkleid bilden Ausnahmen. Bei letzterem handelt es sich wohl nur um ein Versehen der Natur.

Dass bei den Vögeln und Insekten die ästhetische Bildung des Auges und Ohres so himmelhoch Alles überragt, was ihre nächsten Verwandten aufzuweisen haben, rührt im letzten Grunde von ihrem Flugvermögen her, das an die edlen Sinne die stärksten Anforderungen stellt: Sie müssen mit dem Gesicht und Gehör weite Räume beherrschen. Auch hier ist Kraft die Vorbedingung der ästhetischen Funktion. Die grosse Beweglichkeit macht die Vögel und Insekten von dem Zwang der Schutzfarbe in hohem Grade unabhängig und erlaubt ihnen damit den Luxus eines künstlerischen Gewandes. Bei den Säugetieren, deren Gesicht und Gehör durch ragende Pflanzen und die Erhebung des Bodens eingeengt sind, wurde der Geruch als Fernsinn entwickelt, und ihre geringere Beweg- 
lichkeit zwang sie, ihr Kleid dem Aufenthaltsort anzupassen. Und doch ist dieses entwickelte Geruchsvermögen der Säugetiere ohne ästhetische Funktion geblieben. Die Ausdünstung aller Säugetiere ist uns unangenehm oder zuwider, Moschus und Bisam allein ausgenommen. Von den Vögeln gilt ähnliches.

Erst bei den Insekten finden wir den Geruchssinn ästhetisch kultiviert. Die Blume, die für das Insekt da ist, beweist es. Der Mensch ist Schüler und Erbe des Insekts. Es würde ihm vielleicht heute noch Fähigkeit und Gewohnheit, sich an Wohlgerüchen zu erfreuen, gänzlich abgehen, wenn das Insekt ihm nicht vorgearbeitet hätte. Wie ihm ja mit der Blume auch die Materie zur Erzeugung wohlriechender Essenzen bis heute, wo die Chemie aushelfen kann, gefehlt haben würde.

Das staatenbildende, Ingenieurarbeit leistende, Kriegsheer, Sklaven und Haustiere haltende, Vorräte sammelnde, ackerbauende Insekt, das Musik macht und mit der feinsten Empfindung für Farbe begabt ist, steht als eine Art Menschentier unter seinen Verwandten und war vielleicht einmal das intelligenteste Wesen auf der Erde. Kein Zweifel, dass der Vogel von Haus aus dem Säugetier geistig überlegen ist. Aus dem Insekt ist das Höchste nicht geworden, weil es durch seinen Organismus beengt war, aus dem Vogel nicht, weil ihm der Zwang der Not fehlte. Trotz seiner Intelligenz und Geselligkeit ist er zu gesellschaft- 


\section{- I4 -}

licher Organisation im Sinne der Ameisen nicht gekommen.

Wie weit aber das ästhetische Vermögen des Vogels entwickelt ist, beweisen der Rabe, der sich für blanke Objekte interessiert, und der australische Laubenvogel, der sich Museen baut für seine Sammlungen bunter und blanker Dinge, die er von Weit und Breit zusammenschleppt. Vom Hund, von der Katze, die doch schon unsere Intelligenz reflektieren, hat man nie gehört, dass sie silberne Löffel stehlen.

Und was für Opfer bringt der Vogel seinem ästhetischen Bedürfnis! Pfau und Paradiesvögel sind wie Damen, die bei allem Wind und Wetter und bei allen Beschäftigungen seidene Schleppkleider tragen.

Wie denn überhaupt die beiden wichtigsten Motive der menschlichen Kleiderpracht, Krone und Schleppe, die noch heute ein Symbol der höchsten Macht bilden, von den Vögeln schon vorweg genommen sind.

Ich erinnere mich noch deutlich des Tages, wo ich als Kind zuerst einen Pfau erblickte. Ein Märchenschauer überrieselte mich, als ich das stolze Wesen mit der Krone auf dem Haupt und dem wundervollen Schleppkleide vorüberschreiten sah. 
$\mathrm{Ob}$ eine vergleichende Untersuchung über die Entwickelung des Farbensinnes bei den niedrigsten Menschenrassen existiert, vermag ich nicht zu sagen. Fachleute verneinen es. Über die ersten Spuren der Farbenempfindung beim Kinde sind Beobachtungen gemacht, aber, so viel mir bekannt, erlauben sie noch keinen Schluss auf den Moment, wo die ästhetische Freude an der Farbe beim Individuum einsetzt.

Wichtig wäre es, zu erfahren, wie weit sich die Empfindung für Farbe beim Menschen von innen, von der Intelligenz heraus entwickelt, und wie weit der Anblick farbiger Objekte sie angeregt hat.

Kaum zweifelhaft erscheint es jedoch, welche Dinge es waren, deren farbiger Reiz am frühesten empfunden wurde: es war das bunte Gefieder des Vogels, der interessantesten Jagdbeute. Von der Feder, die als Schmuckstück einzeln hinters Ohr oder ins Haar gesteckt wurde, bis zu dem Staatsmantel Montezumas und dem modischen Frauenputz hat das Kleid des Vogels als wertvoller Schmuck stets in Geltung gestanden. Es ist kaum $\mathrm{zu}$ viel behauptet, dass die ästhetische Bildung des Menschenauges mit der Übernahme des künstlerischen Kapitals, das die Vogelwelt geschaffen, einsetzt.

Dann kam ein vielleicht noch kräftigerer Strom künstlerischer Anregung - wohl etwas später - aus dem fernabliegenden Reich der Insekten. Aber nicht durch unmittelbaren An- 
schluss, denn das winzige Insekt interessiert den Menschen nicht entfernt wie der Vogel - die reichen Schmuckstücke, die sich die Indianer Brasiliens aus den prächtigen Flügeldecken grosser Käfer herstellen, sind eine örtlich bedingte Ausnahme - sondern auf dem Umweg über die Blume, die durch das Insekt geworden ist.

Wann mag eines Menschen Auge zuerst mit Wohlgefallen auf der Blume geruht haben?

Jahrtausende werden verstrichen sein, bis der Mensch zur Befriedigung ästhetischen Verlangens blühende Pflanzen angebaut hat, und noch längere Zeiträume, bis er sich bemühte, in seinen Prunkstoffen ihre Farbe nachzuahmen. Das Gleichnis von der Lilie auf dem Felde, die köstlicher angezogen steht als Salomo in seiner Herrlichkeit, ist nicht nur ein wundervolles Bild, sondern auch eine Pforte der Erkenntnis. Der Orientale hatte in seinem wurzelhaften Farbengefühl das Bewusstsein, dass der Glanz seiner Prunkstoffe unmittelbar aus dem Wettstreit mit der Blume entsprungen ist.

\section{s}

Sobald der Mensch anfing, die Blume zu pflanzen und $\mathrm{zu}$ pflegen, um ihrer sicher zu sein und sie nahe zu haben, begann die Epoche der Züchtung neuer Varietäten. Neben der vorhandenen Natur schuf sich der Mensch eine 
zweite, die seinen gesteigerten Bedürfnissen entsprach. Er nahm die Arbeit auf, wo das Insekt sie aufgegeben hatte: jetzt eigentlich erst trat er sein Erbe an.

Diese Arbeit währt nun schon seit Jahrtausenden. Je nach der Kultur und der Begabung der Völker, die ihr oblagen, hat sie die verschiedenartigsten Ergebnisse erzielt, und im Laufe der Geschichte ist sie dem Auf und $\mathrm{Ab}$ der Völkerschicksale gefolgt. Stets war die gezüchtete Blume ein Gradmesser edlerer Gesittung. Am weitesten brachten es in Europa, in Mittelund Ostasien die Bewohner der gemässigten Zone, die Holländer, Engländer und Franzosen, die Perser, Chinesen und Japaner. In den Tropen hat die Natur so reiche und üppige Formen erzeugt, dass das Bedürfnis darüber nicht hinausging. Es wäre der Mühe wert, in geschichtlichen und geographischen Querschnitten zu verfolgen, was die führenden Völker in der Pflege der Blume geleistet haben.

Wie die wilden Blumen von dem farbenempfindlichen Auge der Insekten abhängig waren, so sind es die des Gartens von dem Grade der Kultur, die das Auge ihrer Pfleger erlangt hat. Je feiner organisiert, je höher es ästhetisch erzogen, desto köstlicher die Blume, die es zu seinem Ergötzen zu züchten weiss.

Es ist nicht schwer, die Schwankungen künstlerischen Vermögens und künstlerischer Bedürfnisse von Volk zu Volk, von Geschlecht zu 
Geschlecht festzustellen. Die Blumen von Berlin sind nicht die Blumen von Paris, und die Blumen von 1860 sind nicht die von I89o. Ja, innerhalb des Gebiets jedes einzelnen Volkes und sogar innerhalb des Weichbildes jeder grösseren Stadt lassen sich tiefgehende Unterschiede beobachten.

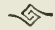

Dass im Zentrum, wo die wohlhabende Gesellschaft Einkäufe macht, die Luxusblumen der Jahreszeit geführt werden, die Orchideen, Euphorbien, Treibhausflieder, Chrysanthemum, die in den weniger wohlhabenden Vierteln keine Abnehmer finden, ist zwar nicht weiter verwunderlich. Aber auffallend ist der Unterschied bei den Hyacinthen, Cinerarien und ähnlichen weniger kostbaren Blumen, die in allen Ständen beliebt sind. Namentlich bei der Cinerarie, der eine besondere Neigung und Fähigkeit innewohnt, ihr Farbenkleid zu ändern, die aber nicht so viel Talent hat wie das Chrysanthemum, das sich, wie es scheint, gegen die Anzüchtung harter und kreischender Töne energisch und mit Erfolg wehrt. Im Zentrum der Stadt stehen die Cinerarien in zarten, geschmackvollen Tönen vor den Schaufenstern, in den entlegeneren Quartieren tragen sie harte, schwere, beissende Farben, genau wie Toiletten der Frauen verschieden sind, die sie geschenkt bekommen sollen, und aus demselben Grunde. 
Wer einmal Gelegenheit hat, die Blumenläden in den verschiedenen deutschen Städten zu vergleichen, der wird zu ähnlichen Ergebnissen kommen. In einer Künstlerstadt wie München oder Düsseldorf, wo es viele Menschen mit erzogenem Geschmack giebt, aber wo Künstler und Künstlerinnen bei grossem Bedürfnis nach Blumenschmuck durchweg keine grossen Mittel zur Befriedigung ihrer Leidenschaft aufwenden können, ist das Blumenmaterial nicht kostbar, aber seit einigen Jahren bemühen sich die Züchter, für ihre ständigen Kunden die prächtigsten der dekorativen Blumen wie Mohn, Gladiolus, Scabiose in Exemplaren von wohlthuender Farbenpracht zu erzielen. In den reichen Städten wie Frankfurt, Berlin, Hamburg wird das kostbare Material der Orchideen und seltenen Rosen bevorzugt; die Mittelstädte pflegen ungefähr auf dem Niveau der Vorstadtkultur der Grossstädte zu stehen. Nichts Schauderhafteres als der bunte, schrille Effekt der Blumenläden in - doch ich will lieber keine Namen nennen. Wieder anders sieht es in den Kleinstädten aus. So weit es Blumenläden giebt und auf den Märkten herrschen die alten Pastors- und Bauernblumen. Hier giebt es wieder eine ruhige, wohlthuende, wenn auch etwas schwere Harmonie, ein Stück Kultur, das aus alten Zeiten herübergerettet ist. Nur wo die Cinerarie schon zur Vorherrschaft gelangt ist, steht es schlimm.

Und wer den Stand der Blumenkultur in 
Deutschland, Belgien, Frankreich und England vergleichend studieren kann, der findet dieselbe Beobachtung aufs neue bestätigt, nur dass die Unterschiede hie und da ins Gigantische wachsen. Auf den ersten Blick würde der Laie die Ergebnisse der Züchtungsmethoden in manchen Fällen kaum für eine und dieselbe Art halten. Die Farbe der Blumen giebt einen sehr genauen Gradmesser für die örtliche Kultur der Farbenempfindung $a b$.

Es ist sehr leicht einzusehen, wie das zusammenhängt.

Auch bei den Blumen wechselt die Liebhaberei von Generation zu Generation. Zur Zeit ist das Chrysanthemum die Lieblingsblume.

In Deutschland, in Belgien, Frankreich und namentlich in England züchten die Blumenliebhaber, die sich den Luxus der Treibhäuser gestatten, diese, wenn man so sagen darf, koloristisch besonders talentierte Blume, die ihre Begabung im langjährigen Kontakt mit dem fein gebildeten Volk der Japaner entwickelt hat. Alljährlich stellen die Liebhaber und die grossen Blumenzüchter ihre neuen Resultate gemeinsam aus, und auf dieser Blumenschau richten dann erzogene Augen. Wo die Augen am schwersten zu befriedigen sind, wie in Frankreich, England und Belgien, müssen die Liebhaber und Blumenzüchter, wenn sie Erfolg haben wollen, sehr grosse Anstrengungen machen und können nur dann darauf rechnen, die unsägliche Mühe und die 
grossen Kosten nicht umsonst aufgewandt zu haben, wenn sie sicher sind, dass sie ein gutes und gebildetes Auge haben. Man darf dort von Chrysanthemumaugen sprechen, wie in Hamburg von Weinzungen und Tabakzungen. Volkswirtschaftlich ist das durchaus nichts Unerhebliches. Die Herrschaft der belgischen Chrysanthemumaugen reicht meiner Erfahrung nach bis Dresden und vielleicht darüber hinaus. Wer in Dresden Freude an vornehmen Farbentönen hat, kauft belgische Chrysanthemum, die er viel teurer zu zahlen hat als die gewöhnlicheren deutschen.

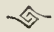

Diese Modeblumen wechseln ständig die Farben und richten sich darin unmittelbar nach dem Geschmack, der in derFrauentoilette herrscht. Wenn fraise écrasée beliebt ist, trägt das Chrysanthemum diese Farbe so gut wie die Bankiersfrau. Und ebenso wird jede andere neue Nuance, die von den massgebenden Augen in Lyon oder London oder Paris der Welt als schön und begehrenswert hingestellt wird, von den Modeblumen zurückgestrahlt. Doch geht es wie bei der Toilette, die in voller Frische und Originalität nur in den Zentren der Produktion auftritt, wo die Bilder gemalt werden, aus deren koloristischen Gedanken sie im letzten Grunde herstammt, und die in Farbe und Form unverständlich und reiz- 
los wird, wenn die Schneiderin irgend einer entlegenen Provinzialstadt sie nachmacht.

Deshalb kann die Berührung mit Modeblumen nur dem erzogenen Auge empfohlen werden und nur dem Grossstädter, der das Beste zur Auswahl hat. Für das erst noch zu erziehende Auge sind die wilden Blumen viel wertvoller.

Sie sollten deshalb eine weit eingehendere Beachtung erfahren als bisher. An ihnen erwacht die Freude an der Farbe zuerst zum Bewusstsein. Denn sie geben sich nicht so leicht wie die Modeblumen, sie wollen umworben und studiert sein.

Und sie vertragen die Vertiefung in ihre Reize besser als die meisten Modeblumen, denn sie verbinden mit der Schönheit der Farbe die Anmut der Form, während die Modeblumen, die auf Massigkeit gezüchtet werden, nur zu oft nichts anderes mehr sind als ein grosser Farbenfleck.

Es wird nicht ausbleiben, dass in den kommenden Jahren der Blumenhandel sich auch der Schätze der Felder, Wiesen und Waldraine bemächtigt. Aber die wahre Freude erlangt doch erst der, der die wilden Blumen selbständig in der Natur beobachtet und sie mit eigenen Händen einheimst. Ihm erst wird die tausendfache Schönheit der bescheidenen Geschöpfe im Herzen aufgehen, und in seiner ästhetischen Erziehung werden sie dieselbe Rolle spielen wie einst in der Entwickelung der Menschheit. 
Die koloristische Erziehung ist aber für uns Deutsche in diesem Moment eine der wichtigsten und notwendigsten Aufgaben. Denn es gilt, eine nationale Schwäche $z u$ besiegen, die uns von unseren koloristisch energischer entwickelten Nachbarn abhängig macht. Gehen wir von der kultivierten Blume aus, so bleiben wir auf lange im Banne der Engländer, Franzosen und Belgier, die die Moden machen.

Wir sollten deshalb auch wünschen, dass unsere Künstler und Künstlerinnen, die Blumenstücke malen, sich mehr als bisher mit den wilden Blumen beschäftigen. Was dem modernen Blumenstücke oft fehlt, der Reiz der Innigkeit, die Poesie, lässt sich an den Modeblumen, die meist ein Element Brutalität enthalten, schwerlich erwerben. Die wilden Blumen bieten obendrein den unendlichen Vorteil, dass sie eigentlich noch nicht gemalt worden sind, wenigstens nicht vom Standpunkt unserer modernen Empfindung für Farbe. 



\section{BLUMENKULTUS}





\section{BLUMEN AM FENSTER}

In den Fischer- und Schifferdörfern, den kleinen Städten und Flecken sehen die Blumenfenster weit schöner aus als in Hamburg. Ich habe wohl äussern hören, wenn einem Touristen der Anblick auffiel, es möge an der eingeschlossenen Luft in diesen Zimmern liegen, dass die Rosen und Nelken, die Geranien, Pelargonien, Pantoffelblumen und anderen altmodischen Blumen sich zu einer so satten Pracht entwickeln. Denn auf dem Lande werden die Fenster selten geöffnet.

Soviel ist richtig, die Blumen, die nicht getrieben werden, gedeihen üppig in der gleichmässigen Luft und Pflege. Aber wenn man dasselbe blühende Geranium, das vor dem Fenster des Bauern in leuchtendem Rot strahlit, zur Stadt brächte, würde es hinter unseren Scheiben nicht anders aussehen als unsere auch.

Die kräftigere Farbenwirkung der Blumen hinter dem Fenster im Schifferhause beruht aber doch nicht auf unserer Einbildung, sondern auf 
einem Sachverhalt in der Wirklichkeit. Der Fischer und Bauer streicht seinen Fensterrahmen noch weiss, er hat noch nicht gleich einem akademisch gebildeten Architekten gelernt, dass das Holz einen trüben, bräunlichen, womöglich holzfarbenen Anstrich bekommen müsse. Das Weiss des Fensterrahmens hebt durch seinen Gegensatz die Kraft des Geraniums und aller Blumenfarben hinter den Scheiben.

Dass die Fensterrahmen in der Stadt wieder weiss gestrichen werden, scheint mir im weiten Felde zu sein.

Wir müssten denn schon in absehbarer Zeit statt der buntscheckig aus Bruchstücken aller Schulen zusammengeflickten Architektur, die nachahmt, was irgendwo Geltung besass, eine Hamburgische Architektur bekommen, deren Urheber sich fragen, was unserem praktischen und ästhetischen Bedürfnis entspricht. Passen weissgestrichene Fensterrahmen in eine schmutziggraue Cementfassade? Passen sie in einen Backsteinbau mit lauter kleinen Formen und Förmchen, die seine Massenwirkung aufheben? Passen sie in die Cementimitationen des Heidelberger Schlosses, in die Cementgotik des imitierten englischen Landhausstils?

Dass die russige Luft sie verbietet, glaube ich nicht. Aus alter Zeit sind sie mitten in der Stadt noch im Gebrauch, wo man es nicht erwarten sollte, so im Schifferwitwenhause am Admiralitätsfleth. 
Aber wer sich draussen in den neu aufgeschlossenen Villengeländen ein Haus baut, der möge sich, wenn er ein Blumenfreund ist, der alten koloristischen Hamburgischen Architektur erinnern, bei der die weissgestrichenen Fensterrahmen in der ruhigen Masse der schlichten unornamentierten Backsteinwand standen, in ihrer Farbigkeit wirkungsvoller als irgend welche plastische Form.

So kann uns der Blumenschmuck des Fensters helfen, die wahre Farbigkeit unserer Architektur zurück zu erobern, die nicht in der Anbringung von bunten Detailformen liegt, sondern in der Bemalung und im farbigen Gegensatz von wichtigen Bauteilen. 


\section{BLUMENLÄDEN}

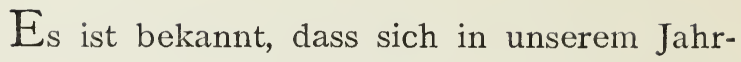
hundert, seit die Spiegelscheiben existieren, eine eigenartige Technik im Aufputz der Ladenfenster entwickelt hat. Wer Gelegenheit hat, die Londoner, Berliner und Pariser Auslagen zu vergleichen, wird einen Unterschied nationaler Schulen feststellen können, und innerhalb der Grenzen einer einzelnen Nationalität drückt sich im Aufputz der Ladenfenster der einzelnen Städte das Niveau der Kultur und der künstlerischen Bedürfnisse aus.

Die Leistungen sind oft gar nicht gering, und wer das Quantum Zeit, Kraft und Mühe, Nachdenken und Erfindungsarbeit zusammenrechnet, das der ständige Wechsel in einer Grossstadt kostet während eines einzigen Monats, der kommt $\mathrm{zu}$ einem fast überwältigenden Resultat.

An den Blumenläden ist die Entwickelung bisher jedoch ziemlich spurlos vorübergegangen. Merkwürdig, man hätte erwarten sollen, dass bei dem künstlerischen Material der Trieb nach Ver- 
vollkommnung dem Ladeninhaber keine Ruhe gelassen hätte.

Aber ein Delikatessenhändler pflegt auf seine Auslage weit mehr künstlerischen Geschmack zu verwenden als der Blumenhändler, sehr seltene Ausnahmen abgerechnet.

Woran mag das liegen? Am Material, das alle Tage gewechselt wird? An der absoluten Unzulänglichkeit oder gar Geschmacklosigkeit - um keinen stärkeren Ausdruck zu brauchen - der Vasen?

Welches die Ursachen sein mögen, die Thatsache lässt sich nicht leugnen, dass die Anordnung des Blumenladens bisher nicht entfernt die im Bereich der Möglichkeit liegenden Kunstmittel ausgenutzt hat. Man möchte fast behaupten, dass die Blumenhändler Kunst überhaupt noch nicht in Anwendung bringen.

Im Interesse der künstlerischen Erziehung des Publikums ist dies sehr zu bedauern.

Die Ladenauslage gehört $z u$ den künstlerischen Erscheinungen, die sich dem Städter auf Schritt und Tritt aufdrängen. Sie ist in dem unaufhörlichen Wechsel ihrer Zusammensetzung ein beständiger öffentlicher Lehrkursus über die Wandlung des Geschmacks, und ohne uns dessen immer bewusst zu sein, empfangen wir von den Ladenfenstern die nachdrücklichsten Belehrungen.

Auf manchen Gebieten, denen der Frauenmode zum Beispiel, ist ihr Anblick eigentlich im höheren Grade ausschlaggebend als der Besuch 
des Ladens. Das Schaufenster markiert nur die grossen Linien der Bewegung. Es kann sich mit den tausenderlei Abschweifungen nicht einlassen, die der Gang der Entwickelung beschreibt. Wenn es wirken will, muss es eine oder die andere Thatsache von Wichtigkeit laut verkünden. Es ist dem Tagesgeschmack prophetisch ein gut Stück voraus. Heute erscheint der Hut, den in einer Woche erst die fortgeschrittenste Dame aufsetzen wird. Die neuen Farbenstimmungen der Hüte, Blumen und Seidenstoffe werden dem Auge in den Auslagen zuerst als das Ziel der neuen Gewöhnung vorgestellt, und hier hat es Zeit, nebenbei und ohne Anstrengung eine alte Gewöhnung zu besiegen und eine neue anzunehmen. Alles vollzieht sich so geräuschlos und rasch, dass es der Mehrzahl gar nicht deutlich ins Bewusstsein kommt.

Das Schaufenster ist um so viel wichtiger als der Ladentisch, weil es sich an alle wendet, nicht verwirren darf und am hellen Tageslicht Teil hat. Man sieht im Fenster am schnellsten und deutlichsten, worum es sich eigentlich handelt.

Voin Schaufenster der Blumenläden kann man nun nicht behaupten, dass es in demselben Sinne eine führende Rolle spielt wie das der Modistin. Vor zehn oder fünfzehn Jahren wurden die bestellten Radbouquets, später die künstlichen Drahtsträusse hineingestellt, heute sind sie vorwiegend mit dem Rohmaterial mächtiger Bündel Nelken, Rosen, Narcissen, Tulpen oder Chry- 
santhemum angefüllt, denen sich in den Zentren der reicheren Städte die kostbaren Orchideen anschliessen. Bei einem Jubiläum oder Benefiz werden wohl auf einen Tag die meist verzweifelt geschmacklosen „Arrangements“ aufgebaut, das ist, um von traurigen Anlässen nicht zu reden, die einzige Abschweifung in das künstlerische Gebiet, und was für ein Abweg meistens!

Die bewegliche und unbewegliche Ausstattung des Blumenladens, von der sich das farbige Material abhebt, ist meist kläglich, wenn sie nicht aus einem Hintergrund von grünen Büschen besteht, der wenigstens nichts verdirbt.

Aus der Zeit des Drahtstrausses giebt es noch Ladenfenster, die wie eine chambre ardente mit schwarzem Sammet ausgeschlagen sind. In München habe ich mit grünem, blauem, rotem oder violettem Sammet wechseln und dann jedesmal der Nuance des ausgestellten Blumenmaterials anpassen sehen. Aber was lehrt das Experiment? Dass man in einem Schaufenster einen glänzenden Effekt mit violettem Sammet erzielen kann, von dem sich eine Sammlung Iris in dunklerem oder hellerem Violett, Lilas und Hellblau abhebt, braucht wohl nicht erst bewiesen $\mathrm{zu}$ werden. Wer diese Iris kauft und mit nach Hause nimmt, wird ihnen diesen Hintergrund weder geben können noch wollen.

Die Idee, im Schaufenster mit dem Hintergrunde zu wechseln, ist an sich nicht übel, und wenn ich mir ein Publikum mit hoch entwickeltem 
Farbensinn denke und einen idealen Blumenhändler konstruiere, der von Haus ein seltenes koloristisches Gefühl und eine ebenso seltene koloristische Phantasie, dazu durch Erziehung den allerfeinsten Geschmack besitzt, so liesse sich vorstellen, wie man in Scharen vor seinem Blumenladen stände, um seine neuen Gedanken aufzunehmen, sich anzueignen und weiter zu tragen. Dies Bild ist kein müssiges Spiel mit Unmöglichkeiten: wo ein Blumenhändler besonderen Geschmack zeigt, sehen wir schon heute seinen Laden umlagert.

Wie solch ein genial begabter Fachmann seinen Laden einrichten würde, lässt sich nicht ausdenken.

Vielleicht würde er ihn behandeln wie eine Zimmerecke mit weisslackierten Vertäfelungen und würde darin auf kleinen Tischen, wie man sie im Zimmer hat, einzelne, einfache, vornehme Vasen mit Sträussen aufstellen, die Schöpfungen seines eigenartigen Talentes. Wenn ihm dann ein Wurf geglückt wäre, den er als die Eingebung einer ganz besonders glücklichen Stunde empfände, dann würde er vielleicht nichts weiter zeigen als dieses eine Kunstwerk, genau wie eine Pariser Modistin, die wohl einmal in ein weiträumiges Schaufenster nichts als einen einzigen Hut stellt. 


\section{BLUMENTÖPFE}

Wenn man vor einem Menschenalter durch die Hamburger Strassen ging, sah man hinter den Fenstern vor den weissen Tüllgardinen je zwei Porzellantöpfe stehen, einen hinter jedem Flügel, und Rosen, Pelargonien, Fuchsien oder seltenere Gewächse erhoben sich daraus, deren kräftigem, gesundem Wuchs man es ansah, dass sie aus Stecklingen im Hause gezogen waren.

Wer genauer zusah, konnte aus mancherlei Unterschieden auf das Lebensalter der Hausbewohner schliessen. Waren die Blumentöpfe aus Fayence mit Löwenmasken, die einen Ring im Maule tragen, dann konnte man ziemlich sicher sein, dass die Pflegerin der Blumen noch die grosse weisse Spitzenhaube trug. $\mathrm{Zu}$ weissem Porzellan mit goldenen Linien und ganz kleinen Löwenköpfchen gehörten drei Locken an der Schläfe. Das alles war altmodisch. Moderne Blumentöpfe um r 870 mussten mit bunten Blumengewinden bemalt sein. Wer sehr fortgeschritten war, stellte keine Pflanzen mehr hinein. 
Wo ist das alles geblieben? In den Strassen, wo die Wohlhabenden wohnen, sieht man kaum eine Spur davon und überhaupt nicht so viel Blumen am Fenster wie früher. Man muss schon in die Vororte oder auf die Dörfer gehen, um die alte Gewohnheit noch am Leben $z u$ finden.

Blumentöpfe ins Fenster zu stellen, war eine besonders norddeutsche Sitte, die wohl ein Jahrhundert geherrscht haben mag und mit der Anlage der Fenster zusammenhängt. An der Seeküste müssen der Stürme wegen die Fenster nach aussen schlagen. Die ältesten dieser Blumentöpfe, die ich mich besinnen kann gesehen zu haben, gehörten in die Gruppe der deutschen Nachahmungen des Wedgewoodsteingutes. Wie die vereinzelt vorkommenden Cachepots des Rokoko oder die Jardinieren aus Fayence derselben Epoche verwendet wurden, weiss ich nicht genau zu sagen. Wahrscheinlich standen auch sie schon im Fenster.

Als man sich bei uns in den siebziger Jahren zur deutschen Renaissance bekehrte, konnte man die Blumentöpfe nicht mehr ausstehen, weil sie aus Porzellan waren. Denn das sechzehnte Jahrhundert, dass nun als massgebend angesehen wurde, hatte das Porzellan noch nicht gekannt. Auch passte das Weiss des Porzellans nicht mehr in die trübe Farbenstimmung, die für altdeutsch und deshalb als allein richtig galt, und die lichten Farben, die der Porzellanmalerei von je natürlich waren, stimmten $\mathrm{zu}$ dem geliebten Lehmgelb, 
Erbsengrün und Wurstrot der Teppiche, Überzüge und Tapeten nicht mehr. Auch die Bemalung mit natürlichen Blumen war verdächtig. Denn nichts war in jener "stilvollen" Epoche so verhasst wie der Naturalismus, von dem die Mädchen in der Schule schon gelernt hatten, dass er sehr verderblich sei. - In der That waren übrigens die letzten Erzeugnisse der Blumentopffabrikation weder in Form noch Farbe geschmackvoll. Schon das Prinzip, das Gefäss, das sich wie ein Postament bescheiden unterordnen soll, mit Blumen zu bemalen, ist nicht zu verteidigen. Und nun die Ausführung!

Es kam hinzu, dass bei den dicht zugezogenen schweren Gardinen, mit denen die Fenster verhängt wurden, die Liebhaberei für Blumen am Fenster zurückging. Mir will scheinen, als ob man sich in der Zeit vorher mit dem Aufziehen aus Stecklingen sehr viel mehr Mühe gegeben hätte. Bald darauf begann auch der weisse Anstrich der äusseren Fensterrahmen und der inneren Leibungen, der zum Blumenschmuck herausgefordert hatte, dem trüben braunen Ton zu weichen.

Dies war wohl der schwerste Schlag, der den Blumenkultus treffen konnte.

Wenn man jetzt die Auslagen der Porzellanmanufakturen in Dresden und Berlin durchmustert, wird man den Blumentopf vergebens suchen. Auch bei den Franzosen scheint der Blumentopf nicht mehr Mode zu sein. Die Engländer und Belgier dagegen haben ihn wieder hervorgeholt 
und ihre Majolikafabriken führen freundliche und billige Waren massenhaft nach dem Kontinent aus.

Für den deutschen Blumenfreund liegt die Frage nahe, ob man bei uns versuchen soll, die alte vergessene Form wieder zu beleben.

Vor dem Fenster können wir den Blumentopf freilich vorläufig noch nicht so gut verwenden wie unsere Eltern, weil es noch nicht wieder von dem Überfluss an Vorhängen befreit und weil es auch nicht wieder in frischen Farben angestrichen wird.

Dagegen haben wir grosse helle Veranden, die mancherlei Blumenschmuck erfordern, und in unseren Zimmern hat der eine Tisch vor dem Sopha einer grösseren Zahl kleiner überall verteilter Tische Platz gemacht, die für die Aufstellung von Blumen sehr bequem sind.

Es lässt sich auch voraussehen, dass die nächste Generation die Architekten zwingen wird, breite Fenster mit hohen Bänken zu bauen, die man nicht mehr verhängen kann und die auf eine reichere Verwendung blühender Pflanzen drängen, schon weil sie dem Auge näher sind als auf den niedrigen Fensterbänken.

Da wird es überall im Zimmer die Möglichkeit geben, einzelne zierliche blühende Gewächse aufzustellen, wie man jetzt einen Strauss hinstellt. 


\section{- 39}

Heute ist dies noch unthunlich, weil uns, wie bisher für die abgeschnittenen Blumen die Vase, für wachsende Pflanzen der hübsche praktische Blumentopf fehlt.

Somit wird es Zeit, uns zu erinnern, dass ein neues Bedürfnis vor der Thür steht.

\section{$-2$}

Soll etwas Gutes entstehen, so muss das Bedürfnis scharf ins Auge gefasst werden.

Blühende Pflanzen im Topf verhalten sich nicht viel anders als abgeschnittene Blumen. Die Hülle des irdenen Gefässes, das die Erde umschliesst, muss sich in Form und Farbe der Pflanze unterordnen.

Ebenso braucht man für blühende Gewächse die verschiedensten Grössen und Formen. Früher war das selbstverständlich. Am Anfange unseres Jahrhunderts waren alle Übergänge von den grössten Kalibern für Rosenbüsche bis zu ganz kleinen für Crocus und Schneeglöckchen im Gebrauch.

Alles seiner selbst wegen Bunte, Prahlende, Dekorierte schadet der Wirkung des blühenden Gewächses, also fort damit! Wie für den Strauss ist hier das Einfachste das Beste.

Fort mit dem Vorurteil, dass nur der kostbare Stoff wertvoll sei. Es gilt, wie überall, aus dem einfachsten wohlfeilsten Material durch 
künstlerische Entwickelung seiner besondern Eigenschaften das Gute $\mathrm{zu}$ erreichen

Das Nächste wird sein, die einfache Töpferware wieder einzuführen, wie es bei den Blumenvasen schon geschehen ist.

Dann wird man sich auf andere Materialien besinnen, die als Topfhüllen zu verwenden sind.

Dass das Bedürfnis wirklich vorhanden, die unansehnlichen porösen, feuchten Thonscherben, in denen die Zierpflanze gezogen wird, zu verbergen, beweist der massenhafte Verbrauch hellgrünen, hellroten, hellblauen Seidenpapiers, in das der Gärtner die Töpfe der schnell getriebenen Maiblumen, Mandelbüsche und Hyacinthen hüllt. Blumenvasen und Gläser führt der Blumenhändler schon längere Zeit, Blumentöpfe noch nicht wieder.

$$
\widehat{\diamond}
$$

Einige Wünsche mögen hier noch ausgesprochen werden. Der Frühling, der in unseren Gewächshäusern zwei Monate früher erscheint als im Kalender und drei Monate früher als in Wirklichkeit, bringt uns eine Schar reizvoller Zwiebelblumen, Veilchen, Primeln, Aurikeln, denen der Blumenfreund gern einen gut beleuchteten Platz in seinem Zimmer geben möchte, ohne sie vom Stengel $\mathrm{zu}$ schneiden. Möge ihm unsere Industrie bald die Mittel dazu an die Hand geben! 
Für den helllilas Crocus braucht er einen Topf mit weisser Glasur, die eine leise Ahnung von Grün enthält, aber nur einen Hauch. Als Schmuck liessen sich zwei lichte grüne Bänder denken, wie ein Tonnenreifen um den Körper geführt.

Der gelbe Crocus braucht einen Topf in sattem Apfelgrün mit zwei Reihen Tupfen in passendem sattem Rot.

Der hartviolette Crocus verträgt ein sehr tiefes Grün oder Rot, auch wohl ein sattes Orange im Ton der eigenen Staubfäden.

Für Schneeglöckchen passt Weiss oder ein Hellgrün, das einen Stich ins Seegrün hat, den Blättern entsprechend.

Tulpen verlangen jenach der vorherrschenden Farbe ein tiefes Purpur, Grün, Rot, Orange.

Für Veilchen ist ein satter Sahnenton mit Flecken von tiefem Krapprot angebracht, auch ein sattes Kaffeebraun passt sehr gut.

Die sechsstengelige lilas Sumpfprimel verträgt ein helles Apfelgrün, das aber nicht zu brillant wirken darf.

Unberechenbar sind die Kombinationen, zu denen die koloristisch so unendlich mannigfaltigen, leider noch nicht wieder in Mode gekommenen Aurikeln herausfordern. 
Wie wir dergleichen erzielen, ist mir noch nicht recht klar.

Wenn die Künstler bei uns Vasen oder Töpfe machen oder nach ihren Angaben herstellen lassen, so werden sie so teuer wie Bilder, während wir Gebrauchswaren nötig haben.

Von den Fabrikanten will ich lieber nicht reden. Es wäre möglich, dass ich ihre Intelligenz, ihren Geschmack, ihren guten Willen nicht so laut preisen könnte, wie sie es selber wünschen möchten.

Mir scheint, es bleibt wieder nur die Hoffnung, dass der gebildete Kunstfreund sich der Sache anninmt. 


\section{BLUMENKÖRBE}

Die Blumenhändler verwenđen Blumenkörbe sehr reichlich. Aber sie sind fast immer absolut geschmacklos, wenn sie einen Schritt über die einfachsten Formen der Bauernarbeit hinausthun.

Und doch liegt hier ein weites Feld für die Erfindung schöner und praktischer Formen und für die Anwendung geschmackvoller Farben offen.

Mir wurde erzählt, man hätte früher in Hamburg statt der Blumentöpfe vor jeden Fensterflügel einen langen eckigen Korb gestellt als Hülle für vier oder fünf Töpfe. Diese Körbe wären innen und aussen grün gestrichen gewesen Gesehen habe ich sie nicht mehr.

Mir scheint die Einrichtung sehr schön und überaus praktisch. Ist der Korb nur stark genug, so kann man die Blumentöpfe sehr leicht an den Ort bringen, wo die Blätter gespült oder abgestäubt werden sollen. Ein flacher Blecheinsatz hält die Feuchtigkeit an, so dass das Begiessen bequem wird. 
Vor allem aber die Farbe. Es ist nichts im Wege, dass man neben dem Grün auch Weiss - das sehr günstig ist - und unter Umständen Rot verwendet oder Weiss mit grünem, Grün mit weissem, Rot mit weissem Querstreifen. Auch Blau, Purpur, Orange und Gelb sind denkbar, aber schwieriger $\mathrm{zu}$ verwenden, sobald man es mit mehr als einer Blume zu thun hat. Hätten wir schon wieder die Gewohnheit, unsere Fensterbänke und Fensterrahmen grün, rot, gelb, blau oder weiss zu streichen, dann würden die Blumenkörbe zwischen diesem Hauptton und dem Grün der Blätter und der Farbe der Blume zu vermitteln haben. Für grössere, alleinstehende Zimmerpflanzen sind Topfhüllen in Gestalt schön bewegterund geschmackvoll gefärbter runder Körbe - Korbvasen - ausgezeichnet verwendbar. Sie sehen gut aus und haben den Vorzug, dass sie nicht zerbrechen.

Unsere Industrie findet hier eine schöne und lohnende Aufgabe, namentlich, da das heimische Material zur Verwendung kommen kann.

In Anlehnung an die herrlichen Vorbilder in der japanischen Abteilung des Museums für Kunst und Gewerbe werden in Hamburg sehr schöne Korbvasen, Fruchtkörbe und Blumenkörbe gemacht. Aber sie genügen noch nicht recht für den praktischen Gebrauch, weil ihre Farbe noch mangelhaft ist und ihre Form zu sehr die japanischen Vorbilder und zu wenig 
unsere Bedürfnisse berücksichtigt. Auch sind sie zu teuer.

Wir sollten versuchen, auch für das heimische Material von den Lehren der Japaner zu profitieren, und dem Blumenkultus eine Reihe bequemer und schöner Formen zur Verfügung stellen.

Mit dem Anstrich müsste vorsichtig verfahren werden, damit sich die Ecken nicht füllen. Was man durch grüne und rote Beizen erreichen kann, weiss ich nicht zu sagen.

$\mathrm{Ob}$ nicht auch in der Korbflechterei ein Arbeitsgebiet für den künstlerischen Dilettantismus $z u$ finden ist?

Es wäre sehr zu wünschen, dass begabte und zur Erfindung neuer Motive oder zur Übertragung der aus einer reichen Phantasie und poetischen Stimmung geschaffenen Motive der japanischen Korbmacherkunst geschickte Kunstfreunde die Korbflechterei lernten. Wäre es auch nur, um dem kleinen Handwerker auf dem Lande oder dem schwieriger zugänglichen Fabrikanten der Grossstadt seine Gedanken klar machen zu können. Es dauert immer furchtbar lange, ehe der Fachmann von selber die ausgetretenen Bahnen verlässt. Der Korbmacher wird in Bezug auf Beweglichkeit und auf die Fähigkeit, Wind und Wetter $\mathrm{zu}$ beobachten, keine Ausnahmestellung einnehmen. 


\section{BLUMENBRETT UND BLUMENGITTER}

In den kleinen Städten von Mittel- und Süddeutschland, wo die Fenster sich entweder nach innen öffnen oder als Schiebefenster in die Höhe gehen, wird das Strassenbild aufs Anmutigste durch die Blumenbretter vor den Fenstern belebt, über deren weiss- oder grüngestrichene Gitter die blühenden roten Geranien und Nelken sich neigen. Es ist dort als Form und Farbe eine der wichtigsten Schmuckformen der bürgerlichen Baukunst, im Zusammenhange der Häuserwand weit eindrucksvoller als jedes denkbare plastische Ornament.

Bei uns in Hamburg lässt sich diese Vorrichtung nicht ohne weiteres übernehmen, weil unsere Fenster von aussen schlagen.

Aber das Blumengitter hat doch auch für uns eine praktische Bedeutung.

Wer im Zimmer eine Fensterbank mitBlumentöpfen füllt, wird bald das Bedürfnis empfinden, die unruhige Reihe der nebeneinander stehenden Töpfe zu verdecken oder als Masse zusammenzufassen.

Dafür giebt es keine bessere Vorrichtung als 
das leichte Gitter aus Holz, mit dem man im Inneren Deutschlands die Blumenbörter abzuschliessen pflegt.

Wer es einmal damit versucht hat, wird sich an dem freundlichen Eindruck erfreut haben.

Für die Verbindung einfacher Formen, die jeder kleine Tischler vollkommen beherrscht, ist ein weiter Spielraum gegeben, und für jede Fensterform lässt sich etwas Eigenes und Originelles ausdenken.

Am zweckmässigsten für die Fensterbank erweisen sich die Gitterformen aus stark deckenden flachen kleinen Latten senkrecht geordnet mit einfach profilierten rautenförmigen Köpfen, die man rot oder grün streicht, je nachdem der Körper weissen oder grünen Anstrich erhalten hat. Rundstäbe sind zierlicher, aber sie decken nicht so gut und sind kostspieliger.

Je mehr die schweren Gardinen von unseren Fenstern verschwinden, desto mehr wird man bedacht sein, den Fensterplatz auszubilden und die Fensterbank wie ein einheitliches Blumenbeet zu behandeln.

Wenn die breite Fensterform mit hohen Bänken, das eigentlich nordische Fenster, erst wieder aufkommt, dann lässt sich das niedrige weisse oder grüne Holzgitter vor den Blumentöpfen auf das Mannigfaltigste abwandeln, und es wird ein Genuss sein, durch die Strassen zu gehen, wo jedes Fenster ein kleines koloristisches Kunstwerk bildet. 


\section{BLUMENGLÄSER}

Seit ganz kurzer Zeit fangen die deutschen Glasfabriken an, billige, nicht immer unpraktische und nicht ganz unschöne Blumengläser und Blumenvasen auf den Markt zu bringen. So weit ich es beobachten konnte, werden sie überall gern gekauft und nicht als Kostbarkeiten, sondern als Verbrauchsware behandelt, wie es sein muss.

Noch sind wir freilich himmelweit davon entfernt, dass der Fabrikant in jedem einzelnen Falle sich überlegt, welchem praktischen und ästhetischen Zweck er genügen will, welche Mittel ihm seine Materie und seine Technik an die Hand geben, um etwas in seiner Art Vollendetes zu schaffen.

So lange mit farblosem Glase gearbeitet wird, geht's noch an. Da kann nur die Form mehr oder weniger praktisch, mehr oder weniger schön sein, und man sieht jetzt hier und da ganz erfreuliche Bildungen, über deren Einfachheit und Zweckmässigkeit man sich freut und wundert. 
Aber sobald die Farbe auftritt, pflegt auch die ganze alte Misere wieder da zu sein.

Was soll man mit einem Blumenglas in Rosa, Lilas, Seegrün und dergleichen Bonbonfarben anfangen? Welche Blume hält die Nachbarschaft solcher flauen, faden, hässlichen Tönchen aus?

Auch alles, was sich der sogenannten Flaschenfarbe nähert, pflegt unerträglich zu sein als Qualität, wenn es sich auch besser als die Bonbonfarben den Blumen unterordnet.

Wer den Versuch gemacht hat, die modernen Erzeugnisse der Glasindustrie praktisch zu verwenden, kommt zu ganz bestimmten Wünschen.

Viele Gläser sind zu dünnwandig. Für grosse, schwere Blumen braucht man mehr Masse, ja sogar eine gewisse Derbheit. Mancher bei dünnwandigen Gläsern flaue oder widerspenstige Glasfluss wird bei dickeren Wänden ohne weiteres kräftig mit dem Blumenstrauss in Harmonie oder Kontrast treten. Oft sieht man für die Aufbewahrung von Schwefelsäure oder anderen Chemikalien grosse Behälter, aus deren Glasfluss man sich ohne weiteres Blumengefässe von kräftigen Formen wünschen möchte.

Dass unsere Glasfabrikation die Eigenschaften des Glases für künstlerische Bedürfnisse - zu denen der Blumenluxus gehört - nicht ausnutzt, liegt wohl an der Unzulänglichkeit der künstlerischen Kräfte, die ihr zu Gebote stehen. Woher soll die Fabrik sie nehmen, die irgendwo in der Provinz liegt weit weg von Kunstzentren, Lichtwark, Blumenkultus, 2. Aufl. 
mit Musterzeichnern, die unsere Gewerbeschulen besucht haben, also wesentlich auf die Anwendung historischer Vorbilder angewiesen sind?

Wenn eine Fabrik sich entschlösse, von einem feinsinnigen Maler die Glasflüsse aussuchen und die Formen bestimmen zu lassen, wie sie für die verschiedenen Blumentypen an Grösse und Umriss passen, so würde das für die Leistungsfähigkeit unserer Industrie ein sehr grosser Gewinn sein. 


\section{BLUMENVASEN}

Zwar werden in jüngster Zeit Vasen und Gläser angefertigt, die das erfreuliche Streben nach Sachlichkeit verraten, aber noch hält es schwer, die Formen und Farben zu finden, die das überaus mannigfache Material der wilden und der gepflegten Blumen verlangt. Bei brauchbarer Form pflegt es mit der Farbe zu hapern, oder umgekehrt, und wenn beides stimmt, lässt unter Umständen das Material des Thons zu wünschen, der nicht immer undurchlässig ist. Dies ist jedoch eine der ersten Bedingungen, dass man die Vase überall aufstellen kann, ohne durch das ausdrängende Wasser das Möbel zu beschädigen.

Die Vase wird immer noch als etwas Kostbares behandelt, als eine rare, selbständige Sache, die möglichst reich geschmückt werden muss.

Wenn ein Künstler sich mit der Herstellung von Vasen befasst, so geht er darauf aus, Schmuck- 
gegenstände zu schaffen, die sich zu einer praktischen Verwendung nicht eignen und sehr teuer werden.

Was wir brauchen, ist aber gerade die billige Gebrauchsware in edler Form und Farbe.

In der Form muss von der Blume ausgegangen werden, die man hineinstellen will. Für Iris, Päonien, Rosen, Nelken, Reseda, Veilchen müssen besondere Formen zur Verfügung stehen, deren Mass und Umriss an dem lebenden Blumenmaterial $\mathrm{zu}$ gewinnen ist. Für manche grossformige Blumen, den Wasserdosten, die grossen Doldenblüten, braucht man grosse Vasen, die nicht auf dem Tisch, sondern auf der Erde stehen. Diese Blumen wirken weniger gut in der Silhouette, als wenn sie von oben gesehen werden.

Profile, modellierte oder gepresste Ornamente sind vom Übel.

Eine schöne, einfache, sachliche Silhouette, ein einzelner starker und schöner Ton der Glasur, das genügt. Die Vase verhält sich zum Strauss wie der Rahmen zum Bilde oder das Postament zur Statue.

Es müsste angestrebt werden, dass diese Vasen in jedem Blumenladen so wohlfeil zur Auswahl stehen, dass man kaum noch einen Strauss ohne Vase verschenkt.

Dass die Vasen in dieser Qualität für einen sehr niedrigen Preis (von dreissig Pfennigen bis $\mathrm{zu}$ einer Mark) in den Handel zu bringen sind, haben die Versuche der Gesellschaft Ham- 
burgischer Kunstfreunde bewiesen. Da sich die Fabrikanten den Vorstellungen verschlossen, hat die Gesellschaft nach den Zeichnungen ihrer Mitglieder Vasen für alle Zwecke bei einfachen Töpfern herstellen lassen. Für die Glasur wurden Töne aus den in der Werkstatt üblichen gewählt. Dass das so oft angezweifelte Bedürfnis dafür vorhanden ist, geht aus der überaus starken Nachfrage hervor. Im Handumdrehen sind die neuen Sendungen jedesmal vergriffen, obgleich keinerlei Anzeigen gemacht werden, und es kann dem Bedarf nicht entfernt genügt werden, denn auch die Blumenhändler haben sich als ständige Abnehmer eingestellt.

Seit die Gesellschaft angefangen hat, ihre Vasen den Schulen zu stiften, namentlich den Mädchenschulen, dringt die künstlerische Pflege des Blumenschmuckes in weite Kreise. Es giebt jetzt schon eine ganze Reihe von Familien, die Dutzende von Vasen im Gebrauch haben, für jede Jahreszeit einen besonderen Satz.

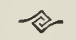

$\mathrm{Zu}$ den Vasen gehört eigentlich auch ein Untersatz, der sie von dem Tisch oder Schrank abhebt. Für kostbarere Erzeugnisse sind die geschnitzten chinesischen unübertrefflich. Für die einfacheren bedient man sich am besten eines flachen schwarzgebeizten hölzernen Tellers. 
Die schwarze Farbe kommt dem Tone der Vase und auch der Wirkung der Blumen ausserordentlich $\mathrm{zu}$ statten. Sehr fein wirkt oft ein sogenanntes „Bricken“ aus Strohgeflecht. Es empfiehlt sich, Untersätze in mancherlei Farben, namentlich in Schwarz und Gelb, zur Verfügung $\mathrm{zu}$ halten. In vielen Fällen ist die Verbindung eines geflochtenen Brickens und eines schwarzen hölzernen Untersatzes von grossem Vorteil. 


\section{TÖPFERKUNST}

Vergangenen Sommer besuchte ich eine kleine Stadt, die als Sitz uralter Töpferkunst bekannt ist.

Die Bewohner lieferten seit mehreren Jahrhunderten einer ganzen Provinz die Gebrauchswaren. Was sie leisten, entspricht den einfachen Bedürfnissen. Aber es ist bei aller Schlichtheit und Sachlichkeit nicht ohne Schönheit. Der durch lange Zeiträume hindurch fortgesetzte Betrieb hatte von selbst $\mathrm{zu}$ ansprechenden Typen geführt, die man als Auslese aus einer unendlichen Zahl von Versuchen wohl begreifen kann. Was in den Kreisen der Abnehmer Beifall fand, wurde immer wieder hergestellt, und in den Töpferfamilien mussten künstlerische Talente sich entwickeln, denn gerade die Kinder wurden mit dem Auftragen der Glasuren betraut.

Wer die Topfmärkte durchmustert, die von diesem Städtchen gespeist werden, findet die originellsten und künstlerisch ansprechendsten Dekorationsmotive einfachster Art, Punkte, Tupfen, Strichel, Flecke in sehr ansprechender und oft ungemein feinfühliger Farbenverteilung, und die 


\section{- $5^{6}-$}

Formen der Geräte sind praktisch und doch nicht ohne Reiz.

Natürlich fand man zur Zeit des ersten Aufschwunges unseres „Kunstgewerbes“, dass die Töpfer in dem entlegenen Nest besserer Vorbildung bedurften, um ihren Absatzkreis zu erweitern. Man hätte freilich besser gethan, in den grossen Städten dem Publikum das Verständnis für die ansprechenden Leistungen des Städtchens beizubringen. Aber ist nicht überall die Reform am verkehrten Ende begonnen?

Es wäre auch immerhin denkbar gewesen, dass man die vorhandenen Keime ausgebildet hätte. Denn auf der Grundlage des Vorhandenen hätte sich sehr wohl eine Töpferkunst aufbauen lassen, die nicht nur dem Geschmack des Kleinstädters und Bauern (der immer noch nicht der schlechteste ist, so lange er naiv bleibt), sondern auch dem Geschmack und dem Bedürfnis des Künstlers entgegengekommen wäre.

Aber das Vorhandene wurde als roh und gemein verachtet. Man wollte Höheres erreichen und gründete $\mathrm{zu}$ dem Zweck ein Keramisches Museum und eine kunstgewerbliche Zeichenschule.

Die furchtbaren Folgen sind nicht ausgeblieben. Hätten die bäuerlichen Kunden des Städtchens ihren alten Geschmack aufgegeben, es wäre keine Spur von der alten Produktion am Leben. 
In dem Keramischen Museum steht am Eingange eine Kollektion von Töpfen und Schalen, wie sie im Jahre vor der Gründung des Museums allgemein hergestellt wurden.

Der Begründer wollte damit der Nachwelt zeigen, aus welchem Verfall die Produktion des Städtchens gerettet werden musste.

Dann folgt eine Auswahl aller scheusslichsten Missgeburten von Zwecklosigkeit und Ungeschmack, mit denen die jüngste Epoche die Welt beglückt hat. Man wandelt durch eine Schreckenskammer kunstgewerblicher Ungeheuerlichkeiten.

Es sind lauter moderne, ganz moderne Sachen, für alte langten die Mittel nicht. Ausserdem: es sollten gerade moderne Vorbilder zum Nachmachen hingestellt werden, damit man konkurrenzfähig würde.

Wer dann zum Eingang zurückkehrt und dort die verachteten Produkte aus der Zeit der Ursprünglichkeit mustert, muss sich gestehen, dass diese die einzig museumsfähigen Dinge im ganzen Institut sind.

So weit sich nach einem Besuch in den verschiedenen Werkstätten ein Urteil fällen lässt, haben Museum und Zeichenschule doch nicht den Schaden angerichtet, der zu erwarten stand.

Die kleinen Betriebe sind bei ihrer alten Art geblieben, weil eben die Abnehmer das Neue nicht wollten.

Eine einzige Werkstatt hat sich auf dem Boden des Museumsbestandes zu einer Fabrik 
entwickelt und liefert die Prunkvasen der Dreimarks- und Fünfgroschenbazare Deutschlands und der Welt.

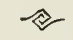

Im selben Sommer verfolgte ich in deutschen Kunststädten die Versuche der Maler, die sich, wie lange vorher schon ihre Kollegen in Paris, mit der Herstellung von Vasen und Tellern beschäftigen.

Was sie bisher hervorgebracht haben, liefert den Beweis, dass von ihnen, das heisst von den Künstlern, und nicht von den Museen und Zeichenschulen, die Rettung unseres Kunstgewerbes kommen muss. Aber sie stehen noch bei den ersten Versuchen und müssen für ihre Erzeugnisse so hohe Summen fordern, dass ihre Arbeit und ihr Geschmack nur einem kleinen Kreise sehr begüterter Liebhaber zu Gute kommen. Auch tragen sie durchweg dem Bedürfnis nicht Rechnung. Sie machen lauter abstrakte Sachen, Vasen an sich, Dekorationsobjekte, die sich weder mit der Form und Farbe der Blumen, noch mit dem Wasser vertragen. Die Meisten sind durchlässig. Was wir zunächst brauchen, ist aber nicht das Prunkgefäss, sondern die künstlerische Veredelung der Gebrauchswaren.

Ein Bedürfnis nach schönen Vasen und Geräten haben in Deutschland vorläufig nur die 
Künstler, die meist keine grossen Mittel aufwenden können, und der gebildete Kunstfreund, der in den reichen Schichten nicht gesucht werden darf.

Soll den Töpfern in den kleinen Produktionszentren geholfen werden, und will man den Künstlern praktische Wege weisen, so sollte man einen der Maler, die sich als Liebhaber in der Keramik bewährt haben, in ein solches Städtchen schicken, dass er Hand in Hand mit den Töpfern die Formen und Dekorationsarten schafft, die einem gebildeten Geschmack Freude machen und doch sich vom Boden des Bedürfnisses nicht entfernen.

Was der Kleinstädter und Bauer braucht, kann im wesentlichen unverändert bleiben.

Für den Grossstädter sollten in dieser Bauernmajolika solche Dinge hergestellt werden, die er nicht lieber aus Fayence oder Porzellan benutzt. Das sind geschmackvolle, einfache und billige Blumenvasen und Blumentöpfe, Deckelgefässe zur Aufbewahrung von Brot und Gebäck aller Art, Salatschalen verschiedener Farbe, denn für Tomaten wird man einen Untergrund anderer Farbe haben wollen als für Gurken oder römischen Salat.

Wenn man in Deutschland mit einem Fachmann über diese Dinge spricht, pflegt er über- 
legen zu lächeln und die ganze Sache mit dem Hinweis von sich abzuschieben, dass so etwas sich wohl ganz hübsch anhöre, aber vom Standpunkte des Geschäfts absolut aussichtslos wäre. Das Publikum sei nicht reif dafür, es habe gar keine künstlerischen Bedürfnisse. Vor allem wolle es das Einfache nicht.

Das ist innerhalb gewisser Grenzen schon richtig. Aber wird es so bleiben, und kann es lange so bleiben?

Wir haben bisher den Fehler begangen, unsere Industrie von der lebenden Kunst abzusperren und an den Leichnam toter Kunst zu ketten. Aber gerade die lebende Kunst muss die einfachen Dinge des täglichen Gebrauchs adeln, wenn sie ihre Rolle in der Volkswirtschaft richtig ausfüllen soll, denn sie ist nicht mehr, wie vor hundert Jahren, die Dienerin des Fürsten und des Hofes.

Dass unser Publikum nicht so tief steht, wie die Fachleute glauben, hat die Aufnahme der einfachen, praktischen und wohlfeilen Blumenvasen der Gesellschaft Hamburgischer Kunstfreunde glänzend dargethan. 


\section{CHRYSANTHEMUM}

Zum zweiten Male hat der erste in Deutschland gegründete Verein von Chrysanthemumfreunden seine Herbstausstellung veranstaltet.

Dass dieser erste Verein in Hamburg entstand, versteht sich für Deutschland eigentlich von selbst. Hamburg hätte sich die Ehre nicht nehmen lassen dürfen. Unsere Blumenliebhaberei hat die älteste Tradition, und ihr Einfluss auf die bildende Kunst und auf die Litteratur war mehr als einmal bahnbrechend.

Der neue Verein scheint sich völlig bewusst $\mathrm{zu}$ sein, dass seine Arbeit ein Kulturwerk ist, denn zur Eröffnung seiner Ausstellung hatte er die Vertreter der höchsten Gesellschaft eingeladen. Der regierende Bürgermeister, Präsident des Senats, hielt die Ansprache, der Protektor des Vereins, Graf Waldersee, sprach die Eröffnungsformel. Unter dem Zeichen der Blume, deren Farbenkleid sich wie eine Toilette der Modedame jeder Bewegung des Geschmackes anschmiegt, die Vertreter aller führenden Stäncic 
um die Ehrendamen des Vereins versammelt zu sehen, darf als ein Beweis für die beginnende Vorherrschaft künstlerischer Interessen gedeutet werden. Denn was interessiert am Chrysanthemum, wenn nicht seine koloristische Begabung?

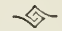

Der Künstler und Kunstfreund wird die Thätigkeit des Vereins mit warmer Sympathie verfolgen und die Ergebnisse seiner Bemühungen mit Dankbarkeit aufnehmen.

Aber er hat auch Wünsche, die hier auszusprechen erlaubt sein mag.

Nach zwei Zielen scheint das Streben der Chrysanthemumzüchter zu gehen, auf die Erzeugung immer neuer Farben und immer grösserer und seltsamerer Formen.

Was die Farbe angeht, kommt kaum ein Missgriff vor.

Aber viele monströse Formen sind nichts weiter als ein grosser schwerfälliger Farbenfleck, und ihre Erzeugung zerstörte den zierlichen Habitus der Staude vollkommen; denn um eine einzige der grossen Blüten zu erzeugen, müssen an der Staude alle Triebe bis auf einen oder einige wenige abgeschnitten werden, und der Blätterschmuck geht fast völlig dabei zu Grunde.

Das wilde Chrysanthemum hat ganz andere Formen. Seine Blumen sind mässig gross oder 
gar klein und sitzen in grosser Zahl, oft zu Hunderten, im satten Grün der dichten Blätter.

Es lässt sich nicht leugnen, dass dieser Typus in sich reicher und künstlerischer ist als das Monstrum aus dem Treibhause.

Nun liegt gewiss in der Erzielung der Riesenform für den Züchter ein technischer Reiz. Aber der Blumenfreund, der von der Kunst kommt, wünscht sich für seinen Genuss noch etwas anderes. Er möchte, dass der Habitus der wilden Pflanzen nicht allzu weit verlassen würde, und wenn er in einer Ausstellung von lauter Enakskindern einen Busch mit tausend kleinen ungefüllten Blüten findet, die in das wohlgepflegte Grün des Blätterdickichts gebettet sind, so geht ihm das Herz auf.

Sollte es nicht möglich sein, dass der Verein unserer Chrysanthemumfreunde nach dieser Richtung neue Pfade einschlägt und neben den kraftstrotzenden Riesenformen auch die zierlichen Buschformen mit vielen kleinen Blüten im dichten Laubwerk zu pflegen unternimmt? Der Spielraum der Farbigkeit würde dabei keine Einschränkung erfahren.

Besondere Effekte wären mit den ungefüllten Formen durch den Kontrast des gelben Zentrums mit den nach der roten, gelben oder blauen Richtung ausweichenden Randblüten zu erzielen.

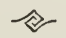


Ob schon ernsthafte Versuche gemacht sind, mit unserem wilden Verwandten des Chrysanthemum $z u$ arbeiten, weiss ich nicht zu sagen. Ich weiss mich nicht darauf zu besinnen.

Aber ich könnte mir denken, dass z. B. unsere Strandaster, die ein wenig aus der Mode gekommen war, weil man zur Zeit der Vorliebe für die "braune Sauce" in Kunst und Industrie kein rechtes Auge für ihr Violett hatte, sich sehr wohl zu Züchtungsversuchen eignen würde, und dass Preisausschreiben in dieser und ähnlicher Richtung das Material an Zierblumen erheblich bereichern und der Hamburger Gesellschaft $\mathrm{zu}$ besonderer Ehre gereichen und $\mathrm{zu}$ grossem Einfluss verhelfen würden.

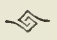

Direktor Brinckmann hatte während der Ausstellung der Produkte unserer Gewächshäuser eine höchst interessante Vorführung von Abbildungen japanischer Züchtungsresultate unternommen. Mit seiner Erlaubnis wiederholen wir an dieser Stelle die Ausführungen, die er den Hamburgischen Tagesblättern darüber gesandt hatte:

"Während die Ausstellung des Vereins der Chrysanthemumfreunde in der ,Alsterlust" ihren Besuchern Gelegenheit bietet, sich lebender Blütenpracht $\mathrm{zu}$ erfreuen, hat das Museum für 
Kunst und Gewerbe fünfzig Abbildungen von in Japan gezogenen Spielarten der herrlichen Blume in japanischen Farbendrucken ausgestellt. Wie grosse Fortschritte die Kultur des Chrysanthemums in Hamburg gemacht hat, erhellt aus der überraschenden Thatsache, dass sehr viele der japanischen Spielarten auch in der ,Alsterlust $\mathrm{zu}$ sehen sind.

Ein Land, in dem seit langen Jahrhunderten Kiku, so heisst Chrysanthemum auf japanisch, als die Wappenblume des Kaiserhauses geehrt und als volkstümlichste Gartenstaude gezogen wird, verfügt natürlich auch über Spielarten, die unseren Kulturen noch fehlen. Mehrere dieser Seltenheiten werden den Besuchern durch die absonderliche Grösse und Form und die auffällige Färbung sofort erkennbar sein. Wie bei uns, hat jede Spielart einen eigenen Namen, und zwar ist dieser Brauch nicht erst den Europäern nachgeahmt. Schon in einem im Jahre 1736 in Kioto gedruckten Buche, das ebenfalls ausgestellt ist, sind hundert verschiedene Spielarten des Kiku abgebildet, aber nicht in Farben, weil damals der japanische Holzfarbendruck dieser Aufgabe noch nicht gewachsen war. Die Farben jeder Blume sind nur in Worten angegeben, dazu die Benennungen. Letztere verdienen die Aufmerksamkeit unserer Chrysanthemumfreunde, die fast durchweg dem trockenen Brauche huldigen, die Neuheiten mit den Namen guter Freunde zu taufen. Nur als sehr seltene Ausnahmen stossen

Lichtwark, Blumenkultus, 2. Aufl. 
wir in der ,Alsterlust' auf Benennungen, die bestimmte, mit der Farbe oder dem Bau der Blüte verknüpfte Vorstellungen erwecken, wie z. B. Avalanche, Schneelawine, für eine grosse reinweisse Blüte; Harvest moon, Herbstmond, offenbar, wie die folgende Benennung, eine Übertragung aus dem Japanischen, für eine mildgelbe, und Golden ball, Goldball, für eine goldgelbe, regelmässig gerundete Spielart. Poetische Ideenverbindungen, wie sie den Japanern nahe liegen, sind bei uns nicht Brauch, verdienten aber feinsinnige Beachtung. Schon vor hundertundfünfzig Jahren nannten die Japaner eine hellrote Kikublüte Asahi, Morgenrot, eine dunkelrot und gelbe Fasogare, Abendsonne, eine weisse Blüte mit besonders langen zierlichen Strahlen Kitashigure, nördlicher Platzregen, eine schneeweisse Blüte mit gelblicher Mitte Yakonotama, nachts leuchtender Edelstein. Unter den heutigen Benennungen der fünfzig Kikuspielarten, die in Farbendruck ausgestellt sind, befinden sich viele alten Dichtungen oder Naturbildern entlehnte Benennungen, die in deutscher Übertragung lauten würden: Sonnenaufgang im Meer (dunkelrot und blassrot), Achtfacher Nebel (weiss, ungewöhnlich feinstrahlig), Löwenmähne (gelb, weiche, mähnenartig verwirrte Strahlen), Tausend Kraniche (weiss, mit sich flügelartig kreuzenden, den Eindruck eines Fluges von Vögeln wiedergebenden Strahlen), Weisse Gewürznelken (eine Spielart, deren Blütenstrahlen sternförmig enden), Glanz 
des Schwertes (weiss, breitblätterige Strahlen), Kaiserliche Goldbrokatfahne (sehr grosse, rote und gelbe Blüten), Herbstliche Ahornblätter in der Abendsonne (leuchtendes Feuerrot und Gelb), Mond im Abendrot (gelbe Scheibe, hellrote und dunkelrote Strahlen), Kämpfende Wellen (weiss, leicht gerötet, wirbelnde Strahlen), Grüne Kiefernadeln (feinstrahlig, hellgrün), Schneepolster auf der Kiefer (rein weiss).

Sachkundige Chrysanthemumfreunde werden die bei uns üblichen Benennungen mit diesen und ähnlichen vergleichen können, die in japanischer und deutscher Sprache bei den ausgestellten Abbildungen vermerkt sind. Sie werden auch an den mannigfachen Anwendungen ihrer Lieblingsblumen im japanischen Kunstgewerbe ihre Freude haben. Einer der Kästen der Stichblättersammlung ist ausschliesslich diesem Motiv gewidmet. 


\section{DER GARTEN AM HAUSE}

An anderer Stelle (Makartbouquet und Blumenstrauss) habe ich darauf hingewiesen, wie arm unsere modernen englischen Gartenanlagen kleinster Dimension an Blumen sind. Büsche, Blattpflanzen und Rasen spielen die erste Rolle. Es werden nur wenige Blumen noch angebaut, und den grössten Teil des Jahres enthalten unsere kleinen Gärten überhaupt keine blühenden Gewächse.

Dabei gestattet uns unser Klima, vom Februar bis zum Dezember Blumen zu haben.

Wir brauchen für das neue Hamburg, das bei dem bevorstehenden Ausbau der Verbindungen sich entwickeln wird, ein praktisches Buch, das uns alle leicht aufzuziehenden blühenden Pflanzen aufführt, die bei uns im freien Lande gedeihen, namentlich die ausdauernden Stauden, Zwiebelgewächse und blühenden Büsche.

Die Tage des englischen Gartens sind gezählt, so bald bei uns eine wirkliche Blumenliebhaberei wieder erwacht, wie sie das siebzehnte 
und achtzehnte Jahrhundert gekannt haben, und die bei den jetzt üblichen Gartenanlagen keine Befriedigung finden kann. Wo soll man die Blumen unterbringen? Die Blume, heute das Stiefkind unseres Gartens, muss wieder wie in alten Zeiten seine Herrin werden.

Und wenn ein Blumenfreund mit dem Gedanken umgeht, sich draussen auf neuerschlossenem Landgebiet ein Haus zu bauen, so wird er vom Garten ausgehend das Haus gestalten, wie es in einen Blumengarten passt, und mit den architektonischen Motiven rechnen, die unsere alte, behagliche Bauweise ihm zur Verfügung stellt.

So kann die Liebe zur Blume uns schliesslich sogar zu einer liebenswürdigen, künstlerischen Weise des Hausbaues zurückführen, denn so bald der Hausherr von seinem Garten wieder Blumen verlangt, ist die klägliche Nachahmung der englischen Landschaft überwunden, und der kleine Garten am Hause kann wieder nach künstlerischen Grundsätzen mit geraden Wegen und Blumenbeeten angelegt werden; und wenn wir erst den künstlerischen Garten haben, muss in der Architektur wieder ein künstlerischer Geschmack zur Geltung kommen.

Von welchem Punkte aus man mit der künstlerischen Erziehung des Auges Ernst macht, man wird, von Kreis zu Kreis fortschreitend, das ganze weite Gebiet auch der hohen Kunst durchmachen. 


\section{DER WINTERGARTEN}

In Deutschland habe ich kaum andere als naturalistische Wintergärten gesehen: ein Stück Wildnis unter einer Glasglocke. Der schönste ist eine Anlage in Gestalt eines Hamburger Gartens mit Rasen aus Farnkraut, Blumenbeeten und einem gelben Kiesweg, der durch ein Palmendickicht auf die Marmortreppe zur Gemäldegalerie führt.

Der Wintergarten ist ein sehr kostspieliges Vergnügen, wenn man seinen Besitz zu den Freuden des Lebens überhaupt rechnen darf. Er pflegt wenig benutzt zu werden.

Vom künstlerischen Standpunkte sind die meisten ebenso ungeniessbar wie die kleinen naturalischen Stadtgärten im sogenannten englischen Stil. Die gewöhnlichen Treibhäuser pflegen unendlich schöner zu sein.

Eine der wichtigsten architektonischen Aufgaben für die nächste Zukunft bildet die künstlerische Ausgestaltung des kleinen Wintergartens. Ich glaube, man wird gut thun, sich an die Mo- 
tive anzulehnen, die die mannigfaltig abgewandelten Formen der Treibhäuser an die Hand geben. Auf diesem Wege wird man am ehesten die Formen finden, die einen behaglichen, bewohnbaren Raum gewährleisten.

Eine andere Möglichkeit läge im Zurückgreifen auf die Formen, die man im vergangenen Jahrhundert für die Orangerien verwendete. Glasdächer gab es damals noch nicht. Die Orangerie hatte grosse, breite Fenster, die, bis zum Boden reichend, viel Licht hereinliessen, und waren mit einer Stuckdecke versehen wie jeder grosse Saal. Diese Stuckdecke hat den grossen Vorteil, dass sie nicht tropft. Bekanntlich pflegen Damen in Gesellschaftstoilette bei grossen Festen nie in die Wintergärten zu gehen, weil sie sich der Gefahr des Tropfenfalls nicht aussetzen wollen. Will man den Wintergarten für die behagliche Benutzung einrichten, so giebt es nichts Praktischeres und künstlerisch Ausbildungsfähigeres als die Form der alten Orangerie mit ihren weissen Wänden und ihren weissen Decken. Eine Wildnis in dieser Umrahmung anzulegen ist unmöglich. Die Verteilung der Bäume und Büsche muss nach architektonischem Gefühl geschehen, und der Gegensatz des Grüns zur weissen Wand, die Verwendung farbigen Lattenwerks (treillage), die Farbe der Kübel geben die Mittel zu einem edlen koloristischen Aufbau, der im wilden Wintergarten, wie er bisher üblich ist, überhaupt nicht angestrebt werden 
kann. In diesem auf der Grundlage der Orangerie entwickelten wirklich brauchbaren Wintergarten werden dann freilich die sperrigen Palmen keinen rechten Platz haben. Aber das schadet ja auch nicht.

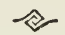

In Hamburg streben die Fachkreise seit Jahren nach der Anlage eines grossen Palmenhauses in Art der Flora bei Berlin oder des Palmengartens in Frankfurt.

Möge der Wunsch nicht in Erfüllung gehen, so lange wir uns unter der Herrschaft der naturalistischen Ideen befinden.

Auch hier wird die Zukunft dem künstlerischen Gedanken gehören.

Das einfachste Motiv für die Anlage eines grossartigen Wintergartens liegt nicht weit: es ist der Kreuzgang unserer alten Klöster.

Eine weite, ebene Fläche, von einer einoder zweistöckigen Säulenhalle eingefasst, auf der ein hohes Glasdach ruht. Die Balkons im ersten Stock mit Blumen geschmückt. Die Palmen regelmässig verteilt auf den Beeten, die die geraden Wege begrenzen: das wird einen behaglichen und jederzeit brauchbaren Aufenthalt geben, der in seinem architektonischen Teil des Kreuzgangs allein Tausenden Platz gewährt, und 
überall wäre Raum vorhanden, Skulpturen als höchsten Schmuck organisch einzuordnen.

Denn man sollte auch einen solchen öffentlichen Wintergarten nicht bloss zum Besehen, sondern für den Gebrauch und für die künstlerische Erbauung einrichten. 


\section{DER WILDE GARTEN}

In den Kreisen der Gesellschaft Hamburgischer Kunstfreunde, die seit Jahren auf eine künstlerische Ausbildung der Blumenpflege hinarbeiten, wird jetzt sehr viel von W. Robinson's in vierter Auflage erschienenem Werk The Wild Garden gesprochen. Prof. Zacharias wies vor längerer Zeit schon darauf hin. Die Ausstellung des letzten Sommers - deren Geschichte in präciser Darstellung der leitenden Gedanken und der Ergebnisse ein Bedürfnis ist - hat uns auch die persönliche Bekanntschaft des liebenswürdigen und feinsinnigen Autors gebracht.

Die jüngste und sicherlich nicht die letzte Auflage des Wild Garden ist von Alfred Parsons reich mit Vollbildern und Textillustrationen versehen, deren Ausführung in Holzschnitt — statt in Autotypie - dem Buch ein sehr einladendes Ansehen verleihen.

W. Robinson betont im Vorwort zur vierten Auflage, dass er vielfach missverstanden wurde. Kein Wunder, da seine Ideen so einfach sind. 
Je einfacher ein Gedanke ist, desto schwieriger pflegt er begriffen zu werden.

Viele Kritiker, sagt er, hielten es nicht der Mühe wert, die eigentliche Absicht zu untersuchen, und einige von ihnen verwechselten den wilden Garten mit dem malerischen. Dieser kann auf mancherlei kostspielige Art angelegt werden, während der Grundgedanke des wilden Gartens in der Auspflanzung von ausländischen Gewächsen besteht, die hart sind wie unsere eigenen wilden Blumen, und in der Wahl von Örtlichkeiten, wo sie sich ohne weitere Mühe und Kosten von selbst üppig entwickeln können.

Es giebt in Ländern, die kältere Winter haben als wir, zahllose blühende Pflanzen von grosser Schönheit, die bei uns so gut wie in der Heimat fortkommen. Wenn wir sie umsichtig heranziehen und die Wiesen, das Unterholz, die Waldränder, Raine, Hecken unserer Parks oder der Umgebung damit beleben, so haben wir fast das ganze Jahr hindurch die herrlichste Augenweide.

Besonders weist W. Robinson auf die herrlichen Zwiebelpflanzen hin, die vor der ersten Mahd auf unsern Wiesen und an den Waldesrändern im Grase gedeihen würden. Bei uns in Deutschland kennen wir kaum den Anblick einer mit dichten Haufen von Narzissen bestandenen Wiese, wie sie Parsons schildert.

Das in höchstem Masse anregende Buch enthält Hinweise auf alle Pflanzen, die sich nach 
des Verfassers Erfahrungen zur Einführung eignen, und bespricht die Ergebnisse von Versuchen, die er auf eigenem Besitz angestellt, und die er bei andern verfolgt hat.

In einem besonderen Kapitel weist er darauf hin, dass für den englischen Garten und Park auch ein grosser Teil der wilden Flora Englands, Schottlands und Irlands $\mathrm{zu}$ den ausländischen Gewächsen gehört. In der letzten Generation sei alles Sinnen und Trachten auf die Einführung subtropischer Pflanzen gerichtet gewesen, die den Winter in England nicht aushalten. Allein auf die Wellingtonie, die doch eigentlich für den englischen Garten gar keinen Wert habe, seien Vermögen verschwendet. Von unsern deutschen Gärten könnte man ähnliche Lieder singen.

Dieser Misswirtschaft gegenüber weist er auf die ungehobenen Schätze der heimischen Pflanzenwelt hin und verlangt deren umsichtige Ausnutzung.

Dabei hört man nirgends den Theoretiker reden. Überall fühlt man, dass aus der Fülle der Erfahrung gesprochen wird, und man sehnt sich bei der Lektüre ordentlich darnach, einmal selber beobachten zu können, was durch des Verfassers Einfluss bereits erreicht ist.

Für Hamburgische Gartenfreunde enthält das Werk eine Fülle willkommener Anregungen. Es ist selbstverständlich, dass die Idee mit grosser Vorsicht und grossem Takt angewendet werden muss. Ohne die Kontrolle eines sichern Ge- 
schmacks könnte sonst leicht eine Karikatur entstehen.

Wir wollen dabei nicht vergessen, dass einige unserer Gartenliebhaber bereits selbständig auf ähnliche Gedanken gekommen sind. In dem reichen Garten von Herrn Blohm in Horn ist ein Teil von W. Robinson's Programm schon verwirklicht, und Herr J. Wesselhoeft hat in seinem Park an der Elbe alle dekorativen Gewächse unserer norddeutschen Wälder und Wiesen systematisch angesiedelt und so mannigfaltige und zarte Effekte damit erreicht, dass manche von Alfred Parsons Illustrationen aussehen, als seien sie dort nach der Natur gezeichnet.

Einem Blumenliebhaber, der mit künstlerischer Empfindung die Blumen betrachtet, eröffnen die Vorschläge von W. Robinson höchst erfreuliche Aussichten. Denn je tiefer wir in das Wesen der Blumen eindringen, desto stärker empfinden wir die Schönheit gerade der „unveredelten" Formen.

Es wäre in unseren Verhältnissen vielleicht denkbar, dass auf dem Lande die Gutsbesitzer in der Nähe grosser Städte mit der Auspflanzung schönblühender wilder Blumen, die sich selbst überlassen bleiben, nicht nur für den Schmuck ihrer Parks und Wiesen sorgten, sondern zugleich ein reiches und höchst willkommenes Material an Schnittblumen für die Blumenliebhaber in der Stadt erzielten. 


\section{DIE HECKENROSE}

Wir pflegen in unseren Gärten blühende Büsche aus allen Weltteilen, Weigelien, Kerrien, Rhododendren, Loniceren, aber keiner von allen kann sich nur entfernt mit unserer wilden Rose messen, und diese habe ich weder in einem Garten noch in einem Park jemals angetroffen, wo sie nicht zufällig im Knick gewachsen war. Wie viele Städter mag es geben, die schon einmal empfunden haben, wie schön ein blühender Strauch der wilden Rose sein kann?

Wo er im Knick oder in der Hecke vorkommt, bedrängt von Schlehen, Weissdorn und Hasel, wo er am Wege steht, von jedem Blumenliebhaber verstümmelt, vermag er seine schönste Form nicht zu entwickeln.

Wer ihn in der Entfaltung der ganzen Schönheit seines Wuchses und seiner Blütenpracht sehen will, muss ihn auf einsamen Heideflächen oder entlegenen Berghalden aufsuchen.

Wenn er dort allein aufstrebt, ungezwängt von Nachbarbüschen und unzerzaust von Vor- 
übergehenden, dann wächst er sich zu einer sehr zierlichen und ganz regelmässigen Gestalt aus, die bei keinem andern Busch vorkommt.

Dicht beieinander schiessen aus dem Wurzelstock schlanke starke Schösslinge empor. In Manneshöhe neigen sie sich mit ihren Zweigen nach aussen und lassen sie in zierlichem Bogen herabhangen. Das bildet dann einen runden Dom von dichten Blättern, ebenmässig und geschlossen, als hätte die Schere des Gärtners ihn unter ihrer Macht.

Zur Blütezeit ist das satte Seegrün dieses Domes mit lichten Rosen besteckt. Die Knospen blühen nicht alle zugleich auf, es kommt nie dazu, dass, wie bei Gartenrosen, die Fülle der Blüten alles Grüne verdrängt und in der überquellenden roten Masse die einzelne Blume nicht mehr erkennbar ist. Jede Blüte der wilden Rose sitzt einzeln wie auf ein grünes Gewand gesteckt und kommt in ihrer Form und Farbe vollkommen und als Einzelwesen zur Geltung. So wirkt ein blühender Busch der wilden Rose nie überladen, und soweit man ihn sehen kann, bleibt der Eindruck derselbe, denn selbst aus weitester Ferne sind in dem tiefen Grün die hellen Flecke der einzelnen Blüten $\mathrm{zu}$ erkennen.

So schön wie die wilde Rose wächst kein anderer Busch, und keiner ist ihm zu vergleichen an Schönheit der farbigen Erscheinung. An die Krüppel, die wir aus der Gartenrose gemacht haben, darf man bei dem Anblick nicht 
denken. Giebt es etwas Hässlicheres als ein Beet hochstämmiger Rosen?

Eine geläufige Formel nennt die Rose Königin der Blumen. Die gefüllte Gartenrose ist es sicher nicht, denn aller Reichtum der Form, alle Anmut der ungefüllten wilden Rose hat die Füllung zerstört. Die Gartenrose ist oft nur noch ein Farbenfleck.

Dass wir sie so sehr bewundern und soviel höher schätzen als alle andern Blumen, geht in erster Linie auf die Überlieferung der alten Welt zurück, und wer an den Ufern des Mittelmeers beobachtet hat, wie die Gartenrose wuchert, der wird verstehen, was aus unserer nordischen Erfahrung schwer einzusehen ist, dass dem Menschen der alten Welt die Rose die Blume an sich war. Ihre dekorative Pracht und Üppigkeit, - Eigenschaften, von denen die Rose im Norden nur noch die stark abgeschwächten Erinnerungen besitzt - ihr Duft, die Zeit ihrer Blüte im Frühjahr erhoben sie zur Blume der Venus, zum Symbol der Liebe.

Heute ist die überlieferte einseitige Schätzung der Rose einem tiefern Verständnis der übrigen Blumen vielfach im Wege. Man ist mit ihnen zufrieden, wenn keine Rosen zu haben sind, und es ist schon ein Zeichen von Selbständigkeit des Geschmacks, wo für eine andere Blume wirklich herzliche Vorliebe herrscht.

Wir sind es so sehr gewöhnt, die Centifolie, die gefüllte Rose als das eigentliche Urbild der 
Gattung anzusehen, dass es den meisten von uns Mühe macht, sich zum Gefühl für die höhere Schönheit unserer wilden Form mit den fünf einzelnen Blumenblättern und dem Kranz gelber Staubfäden darin, emporzuarbeiten. In der Entwicklung des Schönheitsgefühls bedeutet der Tag, wo man das erste Mal beim Anblick einer offenen wilden Rose vergessen hat, dass es gefüllte giebt, einen neuen Abschnitt.

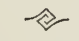

Die wilde Rose in den kleinen Vorstadtgärten einzuführen, wird wohl sobald nicht gelingen. Sie braucht Platz, um ihre volle Schönheit als geschlossener Busch zu entfalten. Wo dagegen in öffentlichen Anlagen ein sonniger Hag zur Verfügung steht, sollten einzelne Büsche wilder Rosen sich frei entfalten dürfen, und nicht zu weit vom Weg.

Wo der Raum dafür ausreicht, kann eine Hecke wilder Rosen von überraschender Wirkung sein. Sie braucht, wo sie Luft hat, wenig Pflege und bietet gegen Wild und menschliche Eindringlinge bessern Schutz als Stacheldraht.

Für die Benutzung als Schnittblume eignet sich die wilde Rose nicht ohne weiteres, weil die Blumenblätter sehr bald abfallen. Dafür blühen aber die Knospen im Glase rasch auf.

Es liesse sich denken, dass unsere BlumenLichtwark, Blumenkultus, 2. Aufl. 
züchter in kurzer Zeit dahin gelangen müssten, ungefüllte Formen zu erzielen, deren Blumenblätter so fest sitzen wie die der gefüllten Formen. Aber das wird noch Weile haben, denn auf dem Blumenmarkt muss, wie auf jedem andern, die Nachfrage vorhanden sein, wenn eine Neuheit sich einführen soll, und dazu bedarf es erst einer Verfeinerung des allgemeinen Geschmacks.

Aber warum sollte die Hoffnung darauf gerade bei der Rose versagen? Was der Hyazinthe und der Dahlia (Georgine) recht ist, ist der Rose billig, und bei der Hyazinthe und der Dahlia haben wir die Wandlung des Geschmacks von der plumpen "gefüllten" zurück zur zierlichen einfachen Form bereits erlebt. 


\section{DER WIESENKLEE}

Seit mit der Entdeckung neuer Länder vom fünfzehnten Jahrhundert ab der seit Karl dem Grossen ziemlich unverändert gebliebene Bestand unserer Blumengärten sich um eine Unendlichkeit erweitert hat, ist es das Ziel der meisten Blumenzüchter gewesen, diese neuen Funde durch die sogenannte Veredelung abzuwandeln.

Unser alter Bestand ist dagegen zurückgetreten, und was die Flora unserer Wiesen und Wälder anlangt, so darf wohl ohne Übertreibung behauptet werden, dass sie für eine feinere Blumenliebhaberei noch nicht entfernt ausgenutzt ist. Und es stecken unsagbare und unerschöpfliche Schätze darin, an denen wir nicht so hochmütig wie bisher vorbeigehen sollten.

Denn wie armselig und eng umrissen ist eigentlich der Umfang der Flora, die in den Blumenläden der grossen Städte auf den Markt kommt. Bei aller Pracht und Üppigkeit des kostbaren Materials legt der Inhalt eines grossstädtischen Blumenladens immer wieder Zeugnis 
ab von der Beschränktheit und Einseitigkeit der Teilnahme. Und überall werden dieselben Arten feilgeboten. Es ist kaum noch ein Unterschied zwischen München und Hamburg. Den thatsächlichen Verhältnissen und dem Bedürfnis entspricht das durchaus nicht. Jede Stadt solite ihre Spezialität haben, jeder Laden sogar.

Es kommt hinzu, dass es im Verlauf des Jahres, sogar des Sommers, immer wieder tote Strecken giebt, wo dem Fragenden geantwortet wird, es giebt jetzt nichts. Die Frühlingsblumen sind abgeblüht, die Sommerblumen noch nicht da. Oder es wird die Armut der Vorräte mit dem Übergang vom Sommer zum Herbst entschuldigt.

Hätten wir schon wieder eine wirkliche Blumenliebhaberei, ein weitverbreitetes Bedürfnis, Blumen im Zimmer zu haben, so würde das Angebot der Nachfrage auf dem Fusse folgen.

Mit der Zeit wird sich der Blumenzüchter wohl doch gezwungen sehen, neue Anregungen statt aus unerforschten, überseeischen Ländern, aus unsern Wiesen und Feldern zu holen.

Und da wird dem gebildeten Geschmack der hohe künstlerische Wert vieler, ihrer Häufigkeit wegen übersehenen Blumen ins Auge fallen, des grossblumigen Wiesenklees zum Beispiel. Wir können kaum ahnen, was sich aus dieser wundervollen Blume durch eine vom künstlerischen Gefühl überwachte Zucht erreichen lässt. In dem saftigen Grün der zierlichen Blätter 
sitzen die Blütenstände mit einem Rot, das an günstigen Standorten in tiefer, glühender Kraft aufleuchtet. Wenn man sich eine Kleepflanze für sich allein vorstellt, wie durch die Pflege der Charakter ihres Wuchses, der auf der Wiese verloren geht, zum vollen Ausdruck entwickelt ist, und ihre Blüten in satter Pracht darin stehen, der wird darin eine Pflanze erkennen, die auf unsern Beeten, in unsern Blumentöpfen und als Schnittblume den bisherigen Bestand wesentlich $\mathrm{zu}$ erweitern bestimmt ist.

Dass der Klee von Haus aus geneigt ist, farbige Spielarten zu erzeugen, beweist die Fülle der Abschattungen seines Rot, das schon auf der Wiese von hellem Fleischton bis zum tiefsten Karmin wechselt. Auch die weisse Spielart kommt auf den Wiesen nicht selten vor.

Es steht mithin zu hoffen, dass eine sorgfältige Behandlung dieser heimischen Wiesenpflanze uns auch koloristisch eine grosse Zahl neuer Genüsse gewähren wird. Denn jede Pflanze hat ja ihre eigene Skala von Tönen, und jede Abschattung giebt sie in eigenartigem Farbenwert. Man könnte von Rosenfarben sprechen, wie von Chrysanthemum-, Cinerarien-, Mohn-, Scabiosen- oder Iristönen. Was zwischen Purpur, Weiss und - vielleicht - Gelb der Wiesenklee an eigenartigen Nüancen aufzubieten im stande ist, hat uns noch kein Blumenzüchter offenbart. 


\section{HECKE UND GITTER}

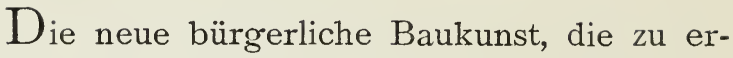
streben unsere Pflicht fordert, ist untrennbar von der Umformung unserer Gärten. Und wie es in der Architektur darauf ankommt, die Punkte zu bezeichnen, wo die Praxis den Hebel anzusetzen hat, so müssen wir auch beim Garten versuchen, die Elemente aufzusuchen für den Aufbau des neuen und ersehnten Gebildes, das mit einer künstlerischen Behandlung des Gebäudes zusammenzugehen hat.

Aufzusuchen, nicht zu erfinden. Es ist alles schon vorhanden gewesen und noch am Leben, wenn auch vergessen und unbeachtet oder doch nicht folgerichtig angewendet.

Unsere kleinen Vorstadtgärten haben keinen künstlerisch gefühlten Abschluss. Sie geben sich nicht als was sie sind, ein kleines eng begrenztes Stück bebautes Land, sondern als ein Stück unendlicher Landschaft. Sie suchen ihre Grenzen zu verheimlichen, über ihren wahren Charakter zu täuschen und erscheinen deshalb nicht grösser, sondern beschränkter als sie sind. 
An der einen Seite bildet das Haus den Abschluss, ihm gegenüber das Gitter nach der Strasse. Hier wie dort giebt es nichts zu verhüllen. Nach den Nachbargärten hin aber werden hohe, breite Gebüsche aufgezogen, womöglich in baumartigem Bestande gipfelnd und in geschwungenen Linien über den Rasen quellend. Soweit es das Gesetz und die Sitte erlauben, wird ein möglichst unberührt erscheinendes Buschwerk auch nach der Strasse hin dem Garten vorgelegt. Viel Platz geht dadurch verloren und im besten Falle lässt sich eine Art Abgeschlossenheit nach den Gartenseiten erzielen.

Das Gitter nach der Strasse ist fast ausnahmslos von Eisen, nicht, wie früher und heute noch auf dem Lande, von Holz. Wirtschaftlich hat das eiserne Gitter, einerlei ob, wie ehedem, gegossen oder, wie heute in der Regel, geschmiedet, sicher den Vorteil. Künstlerisch wirkt das hölzerne Staket unvergleichlich besser, weil es sinnfälligeren Abschluss giebt und als farbige Masse wirkt.

Das eiserne Gitter hat heute noch einen andern Nachteil. Es wird in der Regel schwarz gestrichen, sodass es im Schatten der aufstrebenden Büsche kaum noch sichtbar bleibt. Man fühlt keinen Abschluss mehr.

Will man eine Vorstellung gewinnen von der Wirkung, die ein künstlerisch betonter $\mathrm{Ab}$ schluss des Gartens erzielt, so muss man zu den 
Bauern in der Marsch gehen, bei denen die alte Überlieferung noch nicht überall verschwunden ist.

Sie hegen den Garten doppelt ein durch eine Hecke und ein Staket. Jedes allein würde zur Not genügen. Aber die Hecke hat den Nachteil, dass Hunde und Katzen, von der Dorfjugend zu schweigen, sich Schlupflöcher suchen und durch deren ständige Benutzung die einheitliche Masse der Hecke zerstören, und das Staket allein wirkt mager, namentlich, wenn es grosse Strecken einfriedigt. Das hölzerne Staket steht nun weiss gegen das Grün der sorgsam unter der Schere gehaltenen Hecke. Seltener wird das Staket blaugrün gestrichen, dieser Ton pflegt in der Regel gewählt zu werden, wo etwa unter grossen Bäumen die Hecke hinter dem Staket nicht gedeiht. Holzfarbener Anstrich kommt erst in der jüngsten Zeit vor, von den Bauakademien und Anstreicherschulen mit anderm Unfug eingewandert.

Wer an den flauen Abschluss unserer Gärten, nach den Vorstadtstrassen gewöhnt ist, wird beim ersten Anblick eines alten wohlgehaltenen Bauerngartens etwas wie einen freudigen Schreck empfinden. Wie könnten unsere Strassen aussehen, wenn die Gärten so freundlich abgeschlossen wären.

Freilich werden nicht alle oder nur viele zum hölzernen Staket zurückkehren wollen. Eisen ist dauerhafter. Aber da das Eisen ohnehin einen Anstrich erhalten muss, so ist nicht 
einzusehen, warum die Farbe unter allen Umständen schwarz sein muss und nicht nach künstlerischem Gefühl gewählt werden soll. Wie würden die Hamburger Gartenstrassen wirken, wenn alle eisernen Gitter und Pforten weiss oder grün gestrichen und von der schützenden Fülle der geschorenen Hecke begleitet wären?

Jedenfalls haben wir noch viel zu thun, bis wir in unseren Gartenstrassen aus Gittern und Pforten entwickelt haben, was künstlerisch möglich ist, und vorläufig müssen wir uns begnügen, in unserer Phantasie uns ein Bild von der Schönheit $\mathrm{zu}$ entwerfen, die da möglich und ohne Kosten erreichbar ist.

Gegen die benachbarten Vorgärten pflegt man sich in Hamburg nicht durch Mauern oder Planken abzuschliessen. Diese treten erst bei den grösseren Hintergärten auf, wo sie wohl am Platz sind.

Auch beim seitlichen Abschluss der Vorgärten würde die geschorene Hecke - in beliebiger Höhe - wohl am Platze sein. Zunächst würde sie Raum sparen, der für Rasen und Blumenbeete sehr willkommen wäre. Dann würde sie auf die regelmässige Anlage der Wege und die Verteilung der Beete einen wohlthätigen Zwang ausüben. Wie sich dies Motiv aus- und umbilden lässt, entzieht sich aller Berechnung. Der bildenden Phantasie ist damit ein Spielraum gegeben, den sie bei dem heutigen Naturalismus der Anlage nicht hat, und bei der wechselnden 
G̈rösse des Areals würden alle Übergänge von der niedrigen Hecke bis zur ragenden Laubwand vorkommen können. Für hochstrebende blühende Stauden giebt es kaum einen stimmungsvolleren Hintergrund als die geschoreneLaubwand.

Vor hundert Jahren wurde ein grosser Kampf gegen das Scheren der Bäume unternommen, weil die Freunde der sogenannten freien Gartenkunst sehr richtig fühlten, dass sie mit ihren neuen Gedanken nicht durchdringen würden, so lange die alte Sitte nicht gebrochen wäre.

Wer heute für die Wiederbelebung einer wirklichen Gartenkunst eintreten, wer den für die Kultur unseres Auges so unentbehrlichen Blumengarten durchsetzen will, muss mit der Werbung für die geschorene Hecke und Laubwand und für den farbigen Anstrich der Gitter, Stakete und Pforten einsetzen. 



\section{•}

• 
$\sqrt{ }$ GETTY RESEARCH INSTITUTE

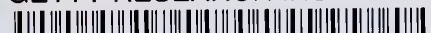




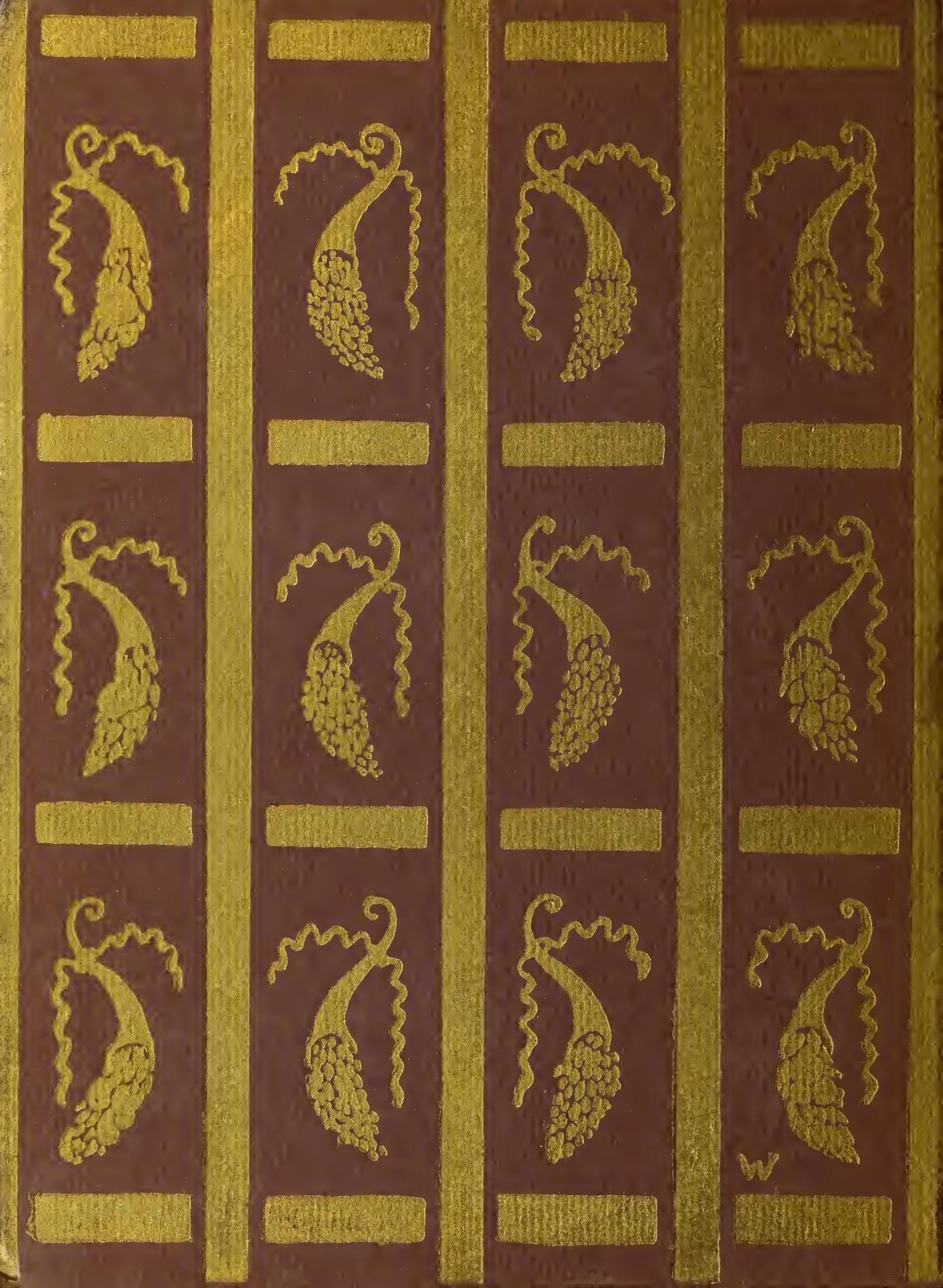

